\title{
Can the Subtropical North Atlantic permanent thermocline be observed from space?
}

\author{
Robin Pingree* $^{\dagger}$, Yu-Heng Kuo* and Carlos Garcia-Soto ${ }^{\ddagger}$ \\ *Institute of Marine Studies, University of Plymouth, Drake Circus, Plymouth, PL4 8AA. ${ }^{\dagger}$ Marine Biological Association, \\ The Laboratory, Citadel Hill, Plymouth, PL1 2PB. ${ }^{\ddagger}$ Centro Oceanográfíco de Santander, Instituto Español de Oceanografía (IEO), \\ Ministerio de Ciencia y Tecnología (MCyT), Promontorio de San Martin s/n, 39004 Santander, Spain. ${ }^{\dagger}$ E-mail: rdpi@mba.ac.uk
}

\begin{abstract}
The analysis of remotely sensed altimeter data and in situ measurements shows that ERS 2 radar can monitor the ocean permanent thermocline from space. The remotely sensed sea level anomaly data account for $\sim 2 / 3$ of the temperature variance or vertical displacement of isotherms at a depth of $\sim 550 \mathrm{~m}$ in the Subtropical North Atlantic Ocean near $32.5^{\circ} \mathrm{N}$. This depth corresponds closely to the region of maximum temperature gradient in the permanent thermocline where near semi-annual internal vertical displacements reach 200 to $300 \mathrm{~m}$. The gradient of the altimeter sea level anomaly data correlates well with measured ocean currents to a depth of $750 \mathrm{~m}$. It is shown that observations from space can account for $\sim 3 / 4$ of the variance of ocean currents measured in situ in the permanent thermocline over a 2-y period. The magnification of the permanent thermocline displacement with respect to the displacement of the sea surface was determined as $-\times 650$ and gives a measure of the ratio of barotropic to baroclinic decay scale of geostrophic current with depth. The overall results are used to interpret an eight year altimeter data time series in the Subtropical North Atlantic at $32.5^{\circ} \mathrm{N}$ which shows a dominant wave or eddy period near 200 days, rather than semi-annual and increases in energy propagating westward in 1995 (west of $25^{\circ} \mathrm{W}$ ). The effects of rapid North Atlantic Oscillation climate change on ocean circulation are discussed. The altimeter data for the Atlantic were Fourier analysed. It is shown how the annual and semi-annual components relate to the seasonal maximum cholorophyll- $a$ SeaWiFS signal in tropical and equatorial regions due to the lifting of the thermocline caused by seasonally varying ocean currents forced by wind stress.
\end{abstract}

\section{INTRODUCTION}

The goals of this study are to determine correlations between altimeter data and in situ ocean measurement of temperature and currents over a 2-y period (1995-1997) at $32.5^{\circ} \mathrm{N}\left(35.5^{\circ} \mathrm{W}\right)$ in the Atlantic Ocean and to describe the structure of temperature and currents in the permanent thermocline over a wider domain. The selective in situ measurements have been interpreted and the results are used to interpret a much longer eight year altimeter data time series (1992-2000) in the region. A knowledge of the vertical displacements of isotherms in the upper ocean is of interest, not least, for determining the propagation of sound in seawater and is therefore of interest to submariners. Isotherm displacement due to dynamic or mesoscale structure of the ocean can significantly affect the distribution of sound speed contours (Spindel \& Desaubies, 1983). The biological application, developed here in Methods, is for SeaWiFS chlorophyll- $a$ data from equatorial and tropical regions where seasonal displacement of the thermocline provides conditions favouring surface primary production. In an earlier paper, we showed that remote sensing of the sea surface in both the visible and infra-red bands could provide data that could be used to determine the structure and development of the seasonal thermocline without making in situ measurements (Pingree \& New, 1995). In this paper, we show that altimeter measurements of the sea surface allow the displacement of, and currents in, the permanent thermocline to be inferred. Some simple regression relationships are derived for the northern Subtropical Gyre region of the North Atlantic Ocean near $33^{\circ} \mathrm{N}$. In recognition of earlier pioneering work comparing altimetry with current measurements (e.g. Stammer et al., 1991), the title for this study is framed as a question and clearly, as in the other cases, the answer is 'yes' but within the bounds of derived criteria for the region considered.

For an accurate appraisal of whether altimeter sea level measurements can accurately represent currents at the sea surface and in the ocean interior, we need access to the raw or uncorrected data because processed data contains smoothing and interpolations in space or time and simultaneous observations are required for optimum correlation with in situ data and subsequent interpretation of results. We also need to make in situ temperature and ocean current measurements and know the quality of the data (i.e. temperature and currents measured on fixed moorings should be carefully calibrated) and extensive data sets $(>1$ year long) are essential. Here, we examine ERS 2 altimeter data in conjunction with 2-y long temperature and current meter records in an upper layer (242 $\mathrm{m}$ depth), in the permanent thermocline (at $742 \mathrm{~m}$ depth) and in the deep ocean interior $(\sim 1368 \mathrm{~m}$ depth) obtained from Rig 155 (Pingree \& Sinha, 2001), deployed in the Subtropical Front region of the North Atlantic Ocean in October 1995 at $32.5^{\circ} \mathrm{N} 35.5^{\circ} \mathrm{W}$.

It is usual to convert altimeter sea surface levels to geostrophic currents using the geostrophic relation. However, 
the sea surface will not necessarily be in a geostrophic balance. There may be sea surface slopes due to other factors, surges or wind set-up for example. There are also currents that can exist without a sea surface slope, e.g. Ekman currents. The ERS 2 data values at a fixed position occur at 35-d intervals. We cannot directly compare derived altimeter currents with values measured by current meters since the current meter will also measure nongeostrophic motions, inertial currents, internal tides and internal waves, for example. In general terms, wind driven currents may dominate a current meter record in the upper layer, with near surface inertial currents or internal waves reaching values in excess of $70 \mathrm{~cm} \mathrm{~s}^{-1}$ in some regions. To compare results from these long current meter records with altimeter derived values it will be necessary to filter out the super inertial frequencies. We might expect the correspondence (or proportionality) between in situ and remote sensing methods to show most agreement at near surface levels. However, since the sea surface may not be in geostrophic balance better correspondence or correlation may occur at deeper levels, depending on the vertical scales for geostrophic motion in the region under consideration. Here, we also compare changes of temperature measured in the upper layer, the permanent thermocline and the deep ocean interior with sea level changes measured by the altimeter (see Kelly \& Watts (1994) using altimeter and IES, inverted echo sounders, for Gulf Stream region). In this case, it is fairly apparent that the deeper internal oscillations will be in quasi-geostrophic balance whereas isotherm displacement or temperature changes at a fixed position near the sea surface will depend on many factors, such as the mixed layer depth, the development of the seasonal thermocline, internal waves and the proximity of the in situ measurements to frontal regions (particularly where temperature and salinity changes compensate for density changes). In anticipation of a working correspondence between temperature and sea level anomaly (sla) measurements, the upper measurements were made at an upper level, below both the mixed layer and the seasonal thermocline, not at the sea surface, thereby reducing the decorrelating effects of nonlinearity and hysteresis. The sla has an annual signal that is related in part to the expansion or the seasonal heat content of the water column and the excess of precipitation over evaporation. For optimum comparison of dynamic internal oscillations with altimetry it will be necessary to remove this climate component or the non-propagating or non-dynamic thermodynamic buoyancy flux component from the total sla signal.

Essentially, this paper presents an unbiased view, starting with unprocessed or raw current meter data and altimeter data, of the degree to which altimeter measurements can predict the movement of isopycnal surfaces and quasigeostrophic currents near the sea surface and in the deep ocean interior. The ocean temperature and current structure at $32.5^{\circ} \mathrm{N}\left(35.5^{\circ} \mathrm{W}\right)$ to a depth of $1400 \mathrm{~m}$ is described and the results showing near semi-annual structure at a fixed point over a $2-y$ period are extended to a $\sim 2000 \mathrm{~km}$ subtropical region over an eight year altimeter data window. The two year appraisal is made using simple linear regression analysis. The proportion of the variance in one variable that can be predicted from variations in another variable is determined (i.e. square of the correlation coefficient, $r$ ).
Here, we answer the questions, how much of the measured in situ variance in ocean temperature and ocean currents can be observed from space and at what depth in the ocean is there most correspondence when using altimeter data as a proxy for isotherm displacements or ocean currents in the subtropical region at $32.5^{\circ} \mathrm{N}$. When this has been done we will then be in a better position to say what the altimeter is detecting in this region, e.g. Rossby Waves, variations in current strength, current meanders, fronts or waves and eddies (Cromwell et al., 1996; Cipollini et al., 1997; Pingree et al., 1999; Cipollini et al., 2000). Although it is shown that the altimeter data can represent the displacement of the permanent thermocline, we make it quite clear that this is an indirect result through correlation with near surface geostrophic velocity and not surface temperature. Indeed, it is shown that the ratio of the surface displacement to the thermocline response is a measure of the ratio of barotropic to baroclinic vertical scales of geostrophic current structure. The dynamic correlation of altimeter structure with sea surface temperature (SST) structure or anomalies is relatively low with respect to correlation with current structure.

In the earlier study (Pingree \& Sinha, 2001), comparisons were made with altimeter derived geostrophic currents from already processed ERS1/2/TOPEX/POSEIDON data. These altimeter data and products were received and used from AVISO (1996) and from the CLS website/ftpsite. Data processing procedures for the latter are described in Le Traon et al., (1998). The final product consists of a Sea Level Anomaly (SLA) referenced to a 3-y mean sea level (which includes the geoid) on a $0.25^{\circ}$ latitude $\times 0.25^{\circ}$ longitude geographical grid over the global ocean at $10-\mathrm{d}$ intervals beginning in October 1992. This final processed sea level anomaly (SLA) product can be converted into global animations of ocean structure and has revolutionized the way we view the ocean, particularly with respect to monitoring ocean climate events like El Niño or La Niña over spatial scales of thousands of kilometres and on time scales of years and the dynamics of mesoscale structure ( $\sim 100-400 \mathrm{~km}$ scale) on time scales of ten days to a year. For the Subtropical North Atlantic region of interest here near $32.5^{\circ} \mathrm{N}$ it was shown that the annual signal is largely stationary and not dynamic so it is convenient to examine the longer eight year altimeter time series with the annual signal removed. It will come as no surprise to oceanographers that there is little annual temperature signal in much of the North Atlantic Ocean below the seasonal thermocline due to the seasonal buoyancy flux at the sea surface. The annual signal will however contain a circulation component in regions where the ocean currents are seasonal. In tropical and equatorial regions, the semi-annual circulation signal can be important and so it will be necessary to examine both annual and semi-annual components. Semi-annual and annual SeaWiFS chlorophyll- $a$ can also be related to the semi-annual and annual altimeter sla signal since the altimeter sea surface elevation structure relates inversely to thermocline displacement.

\section{METHODS AND DATA}

The in situ data are from current meter mooring 155 , deployed at position $32^{\circ} 31^{\prime} \mathrm{N} 35^{\circ} 29^{\prime} \mathrm{W}$ just south of the Subtropical Front or Azores Current (near $34^{\circ} \mathrm{N}$ ) in the 
Subtropical Gyre of the North Atlantic Ocean from RRS 'Charles Darwin' (Cruise CD97 (PML, 1995)). The Aanderaa current meters were at $242 \mathrm{~m}, 742 \mathrm{~m}$ and $1368 \mathrm{~m}$ depth and the measurement depths were considered accurate to $20 \mathrm{~m}$. The three current meters gave good recordings of currents and temperature for $\sim 2$ years (over the period October 1995-November 1997) for comparison with altimeter data. A $400 \mathrm{~m}$ thermistor chain spanned the water column between the upper two current meters. Current values are accurate to $\sim \pm 1 \mathrm{~cm} \mathrm{~s}^{-1}$ and thermistors were calibrated to $\sim \pm 0.03^{\circ} \mathrm{C}$. A conductivitytemperature-depth (CTD) survey in October 1995 showed that at the time of deployment of the mooring, there was a large (400 km major axis) cyclonic eddy (called Storm 0, SO, or reference zero) to the east of the mooring (Pingree et al., 1996) which subsequently moved westward through the mooring region (Figure 1). The CTD positions and instrumentation calibration procedures as well as mooring diagrams are given in PML (1995). In all, four Storm eddies or waves passed the rig position during the 2-y deployment period. The internal displacements of temperature and density to $400 \mathrm{~m}$ were captured using the SeaSoar (e.g. Fasham et al., 1985) which provided a $165 \mathrm{~km}$ vertical section at $32.5^{\circ} \mathrm{N}$ (Figure 2). The section shows clearly the squeezing and stretching of isopycnal separation (or isotherms) at sigma $0=26.5 \mathrm{~kg} \mathrm{~m}^{-3}$ or in the band 26.4 $<\sigma_{0}<26.6$. This dynamic effect is hardly noticeable in the deeper layers, below $\sim 300 \mathrm{~m}$. The $400 \mathrm{~m}$ thermistor chain on Rig 155 provided isotherm structure every $3 \mathrm{~h}$ from $243 \mathrm{~m}$ to $643 \mathrm{~m}$ depth over a period of 265 days. The thermistors were calibrated with a CTD profile (CTD43) alongside the mooring on deployment in November 1995 and with a further CTD profile on 5 June 1996 (CTD 7023, HMS 'Hecla'). In addition, the upper thermistor was only $\sim 1 \mathrm{~m}$ below the upper current meter at $242 \mathrm{~m}$ depth where the temperature was accurately calibrated and so temperature changes over the 265-d period at this level were used to determine the response characteristics of the thermistors. There were three ERS-2 passes within $35 \mathrm{~km}$ of the rig position, 038 and 310 descending, and 088 ascending, and each pass or track is repeated every 35 days. The spread of the passes will result in some loss of correlation with in situ measurement. The passes are nearly northsouth but inclined at an angle of about $13^{\circ}$ on the curved surface of the Earth at this latitude. An Atlantic cross section of temperature conducted from HMS 'Hecla' at $\sim 33^{\circ} \mathrm{N}$ allowed the significance of the results at $\sim 35^{\circ} \mathrm{W}$ to be extended east and west to a $2000 \mathrm{~km}$ region. The T5 expendable bathythermographs (XBTs) used on this section were calibrated with CTD profiles and a bucket SSTreading (Boyd \& Linzell, 1993) on each launching.

\section{Data processing for in situ comparisons}

Each altimeter pass will provide about ten values of sea level anomaly (sla) and sla gradient over a period of a year for comparison with in situ measurements of temperature and current. For a two year current meter record with sampling every $2 \mathrm{~h}$, there are about 8760 current meter values (temperature, east and north component of current). These values were subjected to a $24 \mathrm{~h}$ running mean to remove tides and inertial waves. With three independent altimeter passes only $\sim 60$ of the $24 \mathrm{~h}$ averaged current meter values will be used to compare with altimeter derived quantities for a record two years long. The timing of these $\sim 60$ in situ measurements will coincide (to within $1.5 \mathrm{~h}$ ) with the time of the altimeter passes or observations. Even a cursory glance at an ocean current meter record shows that altimeter interpolations in time are not going to give optimum correlations since large oscillations of current occur on time scales of $>1$ day even with $24 \mathrm{~h}$ smoothing. No interpolations of altimeter data were performed. The sea level anomaly $(s l a)$ was derived in the manner of Pingree \& Sinha (1998) and all available data were used. On each of the three passes, the altimeter data were extracted at $\sim 5 \mathrm{~km}$ intervals along the satellite track and all tidal and atmospheric corrections were applied. To reduce the sampling noise, the sla values were subjected to a $50 \mathrm{~km}$ along track running mean. This smoothing was not significant for the temperature calibrations but because the altimeter data have a root mean square error of $\sim 3 \mathrm{~cm}$ adjacent values cannot be used for slope or gradient values so some regression or averaging is required for geostrophic current estimates. These mean (in space) values of sla were picked off (by computer program) at the latitude of the mooring $\sim 32.5^{\circ} \mathrm{N}$ and the resulting file of sla against time is used for comparison and correlation with the near simultaneous temperature measurements at the three different levels on the mooring rig. A small correction was applied to remove any spatially coherent signal in sea level changes. This largely results from the seasonal heat storage in the upper water column and as a first approximation can be removed by adjusting the sla values with the mean value calculated from $20^{\circ} \mathrm{N}$ to $40^{\circ} \mathrm{N}$ for each of the three passes. The large scale non-dynamic response $(\sim \pm 5 \mathrm{cms})$ to thermohaline change due to the seasonal heat or buoyancy flux (which includes precipitation and evaporation) is thus removed by this method but any local dynamic annual signal related to ocean currents is retained.

To define the derived quantities two simple defining equations are given. For currents, the sla gradient in a direction along the pass was determined to give a geostrophic component normal to the pass using the geostrophic relation, i.e.

$$
\begin{aligned}
& -f \mathrm{u}_{\mathrm{a}}=\frac{g \mathrm{~d}(\text { sla })}{\mathrm{d} a}=\mathrm{g} \theta_{\mathrm{a}} \\
& -f \mathrm{u}_{\mathrm{d}}=\frac{g \mathrm{~d}(\text { sla })}{\mathrm{d} d}=\mathrm{g} \theta_{\mathrm{d}}
\end{aligned}
$$

where $f$ is the Coriolis parameter, $g$ the acceleration due to gravity and $\mathrm{u}_{\mathrm{a}}$ and $\mathrm{u}_{\mathrm{d}}$ are the current components normal to the ascending ( $a$ axis) and descending ( $d$ axis) tracks (positive northwards). $\theta$ is the slope or angle in radians with subscript denoting along the $a$ or $d$ axis. From a correlation point of view, the normal current is proportional to the slope $\theta$ and any level shift or orbit error in sla (over a $>50 \mathrm{~km}$ scale centred on the mooring position) does not affect the derived current but will affect the correlation with measured temperature. So it is quite possible that the altimeter can represent ocean currents (proportional to $\theta$ ) better than sea level variations (measured as sla).

The altimeter $\mathrm{u}_{\mathrm{a}}$ and $\mathrm{u}_{\mathrm{d}}$ components are compared with in situ values by resolving the east $u$ and north $v$ current components measured at the mooring position. Thus 
Table 1. Correlation $\left(\mathrm{r}^{2}\right)$ matrix of altimeter data (sla, slope $=\theta$, proportional to geostrophic current, $u_{g}$ ) and in situ ocean measurements of temperature and currents near the ocean surface $T_{1}$, $U_{1}$, in the permanent thermocline $T_{2}, U_{2}$, and at a deep level, $T_{3}, U_{3}$. See text for details.

\begin{tabular}{|c|c|c|c|c|c|c|c|c|}
\hline & $\mathrm{T}_{1}$ & $\mathrm{~T}_{2}$ & $\mathrm{~T}_{3}$ & $\mathrm{U}_{1}$ & $\mathrm{U}_{2}$ & $\mathrm{U}_{3}$ & sla & $\theta$ \\
\hline $\mathrm{T}_{1}$ & 1 & $\begin{array}{c}1.6 \\
(2420)\end{array}$ & & & & & $\begin{array}{l}920 \\
(44)\end{array}$ & \\
\hline $\mathrm{T}_{2}$ & 0.77 & 1 & & & & & $\begin{array}{l}795 \\
(56)\end{array}$ & \\
\hline $\mathrm{T}_{3}$ & 0.68 & & 1 & & & & (44) & \\
\hline $\mathrm{U}_{1}$ & & & & 1 & $\begin{array}{l}2.6(\mathrm{u}) \\
2.0(\mathrm{v}) \\
(2420)\end{array}$ & & & $\begin{array}{l}1.07 \\
(44)\end{array}$ \\
\hline $\mathrm{U}_{2}$ & & & & 0.80 & 1 & & & $\begin{array}{c}2.5 \\
(56)\end{array}$ \\
\hline $\mathrm{U}_{3}$ & & & & $0.36 / 0.63$ & & 1 & & \\
\hline sla & 0.53 & 0.63 & 0.56 & & & & 1 & \\
\hline$\theta$ & & & & 0.74 & 0.73 & 0.40 & & 1 \\
\hline
\end{tabular}

$u_{\mathrm{a}}=u \cos \alpha+v \sin \alpha$

$u_{\mathrm{d}}=u \cos \alpha-v \sin \alpha$

where $\alpha \sim 13^{\circ}$ is the angle between the altimeter orbit or track over the Earth's surface and the local meridian.

The final altimeter sea level anomaly is referred to as sla and the altimeter geostrophic current $\mathrm{u}_{\mathrm{a}, \mathrm{d}}=\mathrm{u}_{\mathrm{g}}$ (see eqn 1 for definition). The mooring variables are referred to as a surface layer or upper layer with temperature, $\mathrm{T}_{1}$, and current $\mathrm{u}_{\mathrm{a}, \mathrm{d}}=\mathrm{U}_{1}$ (see eqn 2 for definitions), a lower layer, the permanent thermocline, with temperature, $\mathrm{T}_{2}$, and current, $\mathrm{U}_{2}$, and a deep layer with subscript $3, \mathrm{~T}_{3}, \mathrm{U}_{3}$. Correlations $\left(r^{2}\right)$ between relevant variables are given in Table 1 and these $r^{2}$ values form the basis of the paper comparing altimeter results with in situ measurements.

\section{Longer term altimeter and SeaWiFS chlorophyll-a time series}

For examining and interpreting the dynamic structure of the ocean using the longer eight year altimeter data (1992-2000) it is convenient to separate the annual component from the data so as to reveal more clearly the ocean's dynamic response. Both annual and semi-annual signals were extracted by Fourier analysis. For some studies but not in the working area, it will be necessary to discard some higher harmonics caused by tidal aliasing, for example, periods of $\sim 31$ days and $\sim 62$ days. The removal of the annual signal from the eight year record amounts to removing the non-propagating thermodynamic response to the buoyancy flux from the dynamic or propagating components. There is also a circulation component to the annual component that relates to the major ocean current systems. In Pingree \& Sinha (2001), altimeter data for the North Atlantic at $32.5^{\circ} \mathrm{N}$ were Fourier analysed. These results showed that the annual signal at $32.5^{\circ} \mathrm{N}$ was largely related to temperature or rather heat storage and the expansion of the water column and seasonal differences between evaporation and precipitation. A small contribution may result from the gravitational (as opposed to radiation) solar annual tide, Sa. The annual atmospheric tide is effectively removed by the inverted barometer correction applied to the altimeter data which removes the effect of varying atmospheric pressure on sea level changes. The buoyancy signal can be estimated from the local seasonal net heat balance and the balance of precipitation over evaporation. The amplitude for the annual signal is about $5 \mathrm{~cm}$ north of $\sim 17^{\circ} \mathrm{N}$. The seasonal amplitude determined from the sla data was also checked against CTD dynamic height data for the region of interest. Six CTDs stations at fixed latitudes $\left(30^{\circ}-37^{\circ} \mathrm{N}\right.$, near $\left.28^{\circ} \mathrm{W}\right)$ in mid October (PML, 1995) gave a mean dynamic height of 177 dyn.cm (2000 dbar reference level) for either side of the Storm or Azores Current meander latitude $\left(\sim 32^{\circ}-35^{\circ} \mathrm{N}\right)$. At the same CTD stations positions in March (Pingree, 1997), a mean dynamic height of 166 dyn.cm was determined. Similar station positions for late April (Mouriño et al., 2002) gave a value of 168 dyn.cm. The conversion factor for $1 \mathrm{~cm}$ is 0.98 dyn.cm so the measurements also give an annual amplitude of $\sim 5 \mathrm{~cm}$. Estimates can also be made from seasonal CTD profiles in the region. In the vicinity of Great Meteor Tablemount at $30^{\circ} \mathrm{N}$, for example (Mouriño et al., 2001), the heat stored in the upper water column,

Figure 1. Position of Rig 155 in relation to ERS 2 passes 038,088 and 310 . The $10^{\circ} \mathrm{C}$ isotherm, which represents the displacement of the permanent thermocline or layer 2, is shown for the period 19-30 October 1995 . The centre of Storm 0 (also S0) is near $32.5^{\circ} \mathrm{N} 33.5^{\circ} \mathrm{W}$ and this isotherm is raised about $200 \mathrm{~m}$ with respect to external regions. The ' 0 ' signifies that this is the reference or first cyclonic eddy of the repeating structure to be surveyed with CTDs/Lagrangian floats and then identified in altimeter remote sensing data. The lines are cruise tracks of RRS 'Charles Darwin' from yearday 292-303 (1995). The structure to the north-east shows the tilting of the permanent thermocline associated with the Subtropical Front or Azores Current. Figure 2. SeaSoar vertical section of depth (pressure in dbar) of isopycnals $\left(\sigma_{\mathrm{o}} \mathrm{kg} \mathrm{m}^{-3}\right.$ ) against time (yearday 300 and hour on 27 October 1995 ) obtained as RRS 'Charles Darwin' (CD 97) steamed westward along $32.5^{\circ} \mathrm{N}$ from $33.8^{\circ} \mathrm{W}$, near the centre of Storm 0 (indicated by ' 0 ') to $35.5^{\circ} \mathrm{W}$, just past the position of Rig 155. The section shows the displacement of the upper layers over a distance of $165 \mathrm{~km}$ obtained from $\sim 120 \mathrm{CTD}$ profiles, covering $\sim 1 / 3$ of the oscillation wavelength (distance between consecutive high or low pressure anomalies) in this region. $\left(\sigma_{0}=26.5\right.$ corresponds closely with $17.5^{\circ} \mathrm{C} ; \sigma_{\mathrm{o}}=26.8$ with $15.0^{\circ} \mathrm{C} ; \sigma_{\mathrm{o}}=27.0$ with $13.0^{\circ} \mathrm{C}$ ). 


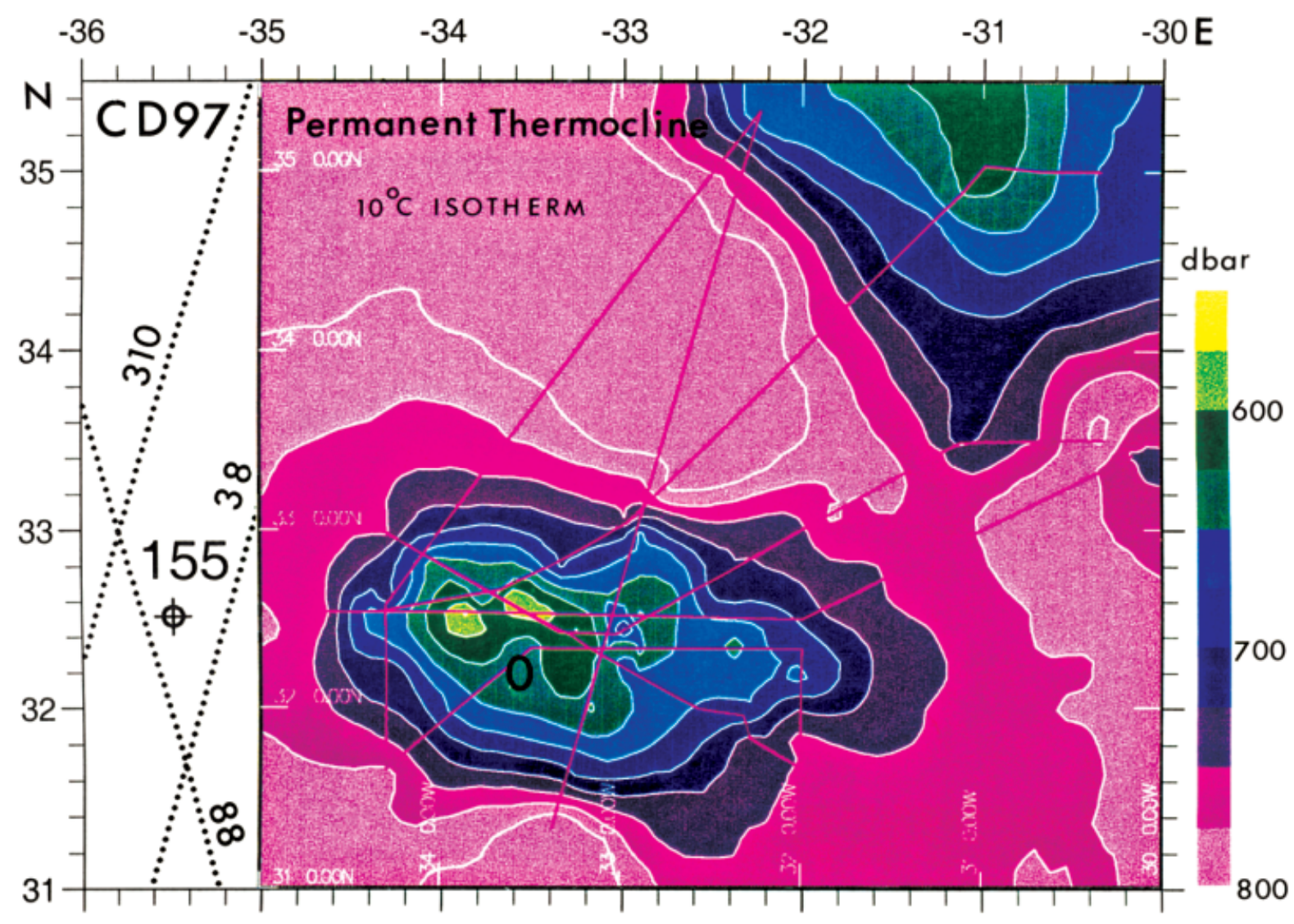

Figure 1.

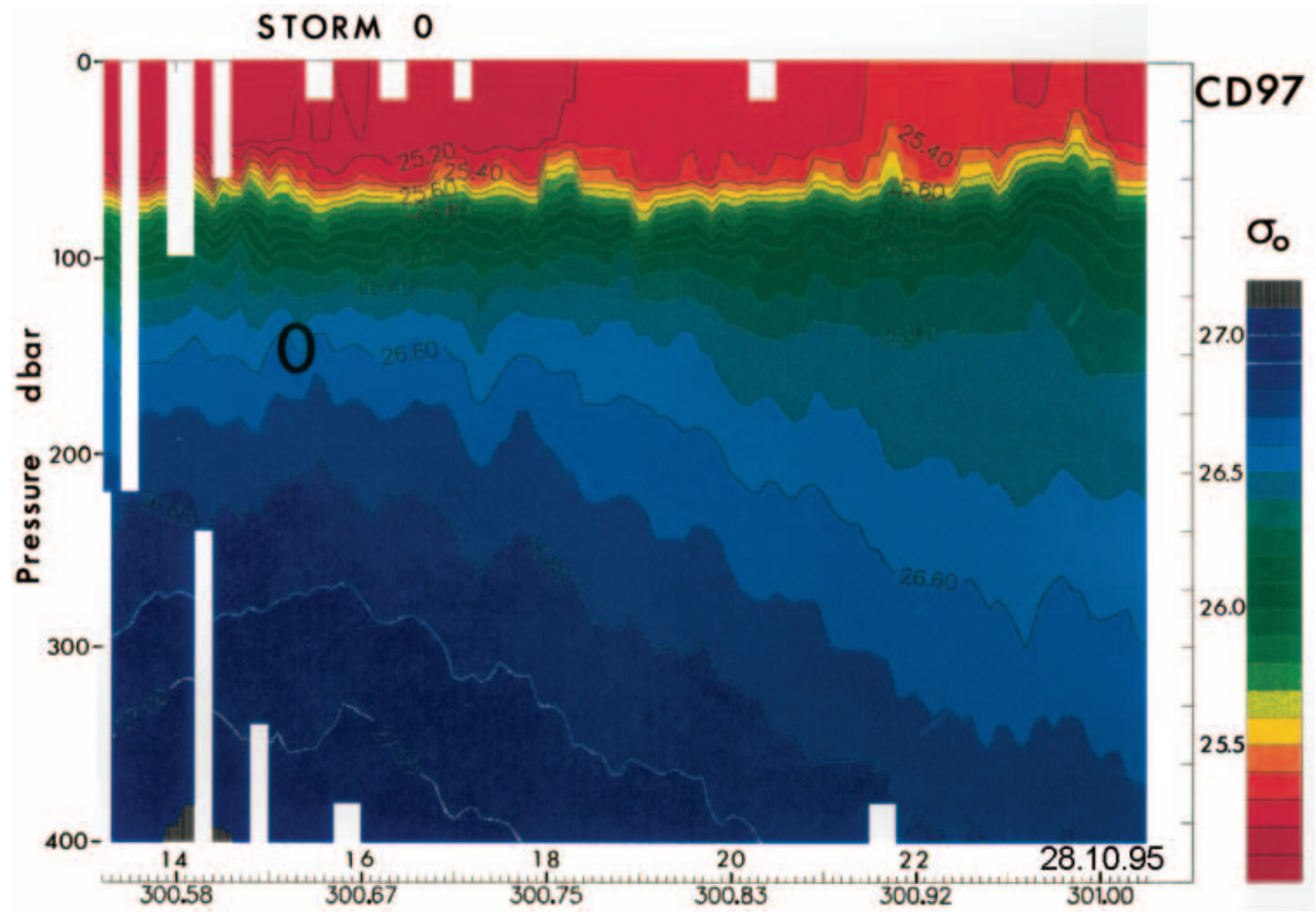

Figure 2. 
with a maximum in October when the surface mixed layer temperature was $25^{\circ} \mathrm{C}$ (minimum in March with a temperature of $19^{\circ} \mathrm{C}$ ), gave an annual signal of $\sim 4.8 \mathrm{~cm}$. Salinity values, with surface values ranging from $36.8 \mathrm{psu}$ (March) to $37.1 \mathrm{psu}$ (October), showed that density changes due to seasonally varying salinity (assumed to result from local changes) were $\sim 20 \%$ of the temperature changes giving a total amplitude of $\sim 6 \mathrm{~cm}$ which is the value observed in the altimeter data at this position of generally weak circulation or small advection flux contributions to the local heat and salt budgets.

As expected, this signal is fairly uniform spatially (without phase difference) so large elevation gradients and with large geostrophic currents are not established. The annual signal does not propagate westward in the subtropical region near $33^{\circ} \mathrm{N}$ but is established almost simultaneously across the ocean with generally increasing amplitude in the west with an advanced seasonal tendency or phase related to the Gulf Stream (Figure 3). There is also a corresponding one month advance of phase in the seasonal SeaWiFS signal in the west (Gulf Stream) so these effects are important in the timing of the spring bloom at subtropical latitudes. In the Subtropical region of interest here, maximum zonal elevation gradients were of order $2 \mathrm{~cm}$ or $3 \mathrm{~cm}$ in $500 \mathrm{~km}$, or slope $\theta \sim 5 \times 10^{-8}$, resulting in a northerly geostrophic current component of $< \pm 1 \mathrm{cms}^{-1}$. By contrast, it was shown in Pingree \& Sinha (2001) that the measured north component of current of the westward propagating signal in the 180 to 210 day wave period band was of the order $\pm 25 \mathrm{~cm} \mathrm{~s}^{-1}$. In this case, the propagating or dynamic signal is several hundred times more energetic than the annual climate signal.

Similarly, the annual signal at $35^{\circ} \mathrm{W}$ is not propagating in the region $17^{\circ} \mathrm{N}-45^{\circ} \mathrm{N}$ (Figure 4) though at this longitude the equatorial region with weaker amplitude $(\sim<2 \mathrm{~cm})$ between $10^{\circ} \mathrm{N}$ and $15^{\circ} \mathrm{N}$ (North Equatorial Current (NEG) region) is out of phase with the northern region and the annual signal propagates westward in this latitude band, west of $35^{\circ} \mathrm{W}$. Other meridional sections (not shown) showed that in the region of West African upwelling at $\sim 17.5^{\circ} \mathrm{W}$, still near $10^{\circ} \mathrm{N}$ to $15^{\circ} \mathrm{N}$, the annual signal increased locally to $8 \mathrm{~cm}$ (near $14^{\circ} \mathrm{N}$ ) and the annual signal propagated rapidily westward but only to $\sim 20^{\circ} \mathrm{W}$. The annual amplitude near $3^{\circ} \mathrm{N}$ was enhanced $\sim 10 \mathrm{~cm}$ in the Equatorial Counter Current (ECG)/South Equatorial Current (SEC, which becomes the Guiana Current or North Brazil Current in the west) region, comparable with Gulf Stream influence levels which contribute to a maximum annual amplitude of $\sim 15 \mathrm{~cm}$. The current system near $3^{\circ} \mathrm{N}$ (Figure 4) is anticyclonic particularly in the Northern Hemisphere summer when the ECG originates further westward and this causes the amplitude elevation mound reaching a maximum of $12 \mathrm{~cm}$ at $41^{\circ} \mathrm{W}$. The sla annual phase is such that the annual changes in SEC/ ECG circulation is less clockwise in March with the ECG originating further east $\sim 20^{\circ} \mathrm{W}$, rather than at $44^{\circ} \mathrm{W}$. There is also an annual and semi-annual period elevation amplitude maximum along the equator to the east of $25^{\circ} \mathrm{W}$ which corresponds to a region of equatorial upwelling or thermocline lifting and enhanced mean SeaWiFS chlorophyll- $a$ levels. The SeaWiFS annual and semi-annual signals follow the sla equatorial negative (upwelling or cool) structure giving two blooms, one in December/January and the dominant one in July/August $\sim 10$ days after lowest sea level $(\sim-8 \mathrm{~cm})$.

Developing further, the semi-annual signal can become dominant and exceed the annual amplitude in tropical and equatorial regions. For example, in the NEC region and between $6^{\circ} \mathrm{S}$ and $6^{\circ} \mathrm{N}$, mainly in the Eastern Atlantic, east of $20^{\circ} \mathrm{W}$. The latter region includes the Guinea upwelling zone off Africa (between Abidjan and Accra with upwelling in January and August, Hydrographic Department (1982)), with a maximum amplitude reaching $5 \mathrm{~cm}$, and this maximum extends westward across the Atlantic at $4^{\circ} \mathrm{N}$ with a local maximum amplitude of $\sim 3 \mathrm{~cm}$ to the North Brazil Current retroflection region (Richardson et al., 1994). There is also a region from near the Congo Canyon $\left(\sim 6^{\circ} \mathrm{S}\right)$ with amplitude of $4 \mathrm{~cm}$ which extends westward from Gabon $\left(\sim 10^{\circ} \mathrm{E}\right)$ at $2^{\circ} \mathrm{S}$ to the Equator at $25^{\circ} \mathrm{W}$. Although these amplitudes may appear small, eqn 1 shows that the associated geostrophic currents are significant since $f$ is small near the equator. We estimate a zonal semi-annual current component of $\sim 10 \mathrm{~cm} \mathrm{~s}^{-1}$ for the Guinea Current at $4^{\circ} \mathrm{N}$, based on altimetry, and a similar value resulting from the annual component. The phases of the annual and semi-annual signal were derived relative to the start of the year (1 January). The phase of the semi-annual signal is such that lower sea level occurs in early February and early August in the Guinea region (near Ghana), periods corresponding to the timing of the upwelling. The annual signal with phase $\sim 30^{\circ}$ makes August the dominant low or upwelling period. Similarly analysed annual and semiannual SeaWiFS data (4-y time series), with blooms in February and August, makes August the dominant bloom period with chlorophyll- $a$ maximum $\left(\sim 1.5 \mathrm{mg} \mathrm{m}^{-3}\right)$ coming $\sim 10$ days after the lowest seasonal sea level $(\sim-10 \mathrm{~cm})$ in the Guinea upwelling zone. A similar Fourier analysis for the SeaWiFS Congo Plume data $\left(\sim 4-5^{\circ} \mathrm{S} \quad 0-10^{\circ} \mathrm{E}\right)$ showed a SeaWiFS chhlorophyll- $a$ maximum in late July (with a second seasonal maximum in January) forced by thermocline displacement (sla minimum) but tilted (sla maximum gradient) due to SEC seasonality with maximum flow to the west in July also drawing out the Congo Plume source region. Overall, the semi-annual sla structure is mainly zonally propagating, but north of $25^{\circ} \mathrm{N}$, the wave number structure is relatively high (wavelength $\sim<600 \mathrm{~km}$ ), whereas south of $20^{\circ} \mathrm{N}$, or in tropical and equatorial regions, the wavelength scale is of order the Ocean width or $\sim>2000 \mathrm{~km}$.

To the north (see Figure 4), the amplitude of the annual component shows some important dynamic structure associated with local meridional maximum structure at $48.5^{\circ} \mathrm{N}$ associated with the North Atlantic Current. In the $20^{\circ} \mathrm{N}-40^{\circ} \mathrm{N}$ region at $35^{\circ} \mathrm{W}$, there are meridional elevation changes of about $2 \mathrm{~cm}$ over scales of $1000 \mathrm{~km}$ which will result in easterly geostrophic currents of $< \pm 1 \mathrm{~cm} \mathrm{~s}^{-1}$ in the subtropical study region. Of interest here is the local maximum amplitude region near $35^{\circ} \mathrm{N}$ with gradients equivalent to $\sim \pm 4 \mathrm{~cm} \mathrm{~s}^{-1}$ near $34^{\circ} \mathrm{N}$. This is the surface seasonal variation for the Subtropical Front outcrop or Azores Current (AC) as observed by the altimeter. It could result from several mechanisms: (1) a north-south displacement of the $\mathrm{AC}$; (2) a winter intensification of the AC; (3) a deepening of the mixed layer revealing a 
subsurface maximum of the AC; (4) erosion of the seasonal thermocline so that $18^{\circ} \mathrm{C}$ source water for the $\mathrm{AC}$ flows at the sea surface where its isopychal outcrops. (2) and (4) have been observed (Pingree, 1997). The same structures could be interpreted as an increasing anticyclonic (summer) cyclonic (winter) tendency centred near $35^{\circ} \mathrm{N}$ but rather more intense to the south. The local amplitude minimum at $\sim 33^{\circ} \mathrm{N}$ can be interpreted as evidence for a southern AG Counterflow region near $32.5^{\circ} \mathrm{N}$. Although there is noise still present in the annual signal derived from an eight year time series, this basic AC structure was evident from $25^{\circ} \mathrm{W}$ (local maximum amplitude near $35^{\circ} \mathrm{N}$ ) to $43^{\circ} \mathrm{W}$ (local maximum amplitude near $38^{\circ} \mathrm{N}$ ) with a local minimum amplitude region from $30^{\circ} \mathrm{W}$ to $38^{\circ} \mathrm{W}$ near $33.5^{\circ} \mathrm{N}$. In the study region near $33^{\circ} \mathrm{N}$, meridional gradients are equivalent to $\sim \pm 1 \mathrm{cms}^{-1}$ zonal current variations with time. For these reasons, when examining or appraising the dynamic structure from the much longer altimeter data sets that do not have matching Eulerian data it is convenient to remove the annual signal thereby enhancing the dynamic signal, though the annual signal itself shows important seasonal changes in ocean circulation in major current regions. So in summary, the annual signal includes both the seasonal changes in ocean currents and the almost passive stored buoyancy. The residual, with the annual component removed, contains the dynamic eddy and wave structures at $32.5^{\circ} \mathrm{N}$. Indeed, all the major current systems in the world's oceans can be identified by their annual and semi-annual seasonal variations. Remarkably in the Pacific, the North Pacific Current showed two branches or maximum amplitude regions around $150-180^{\circ} \mathrm{E}$, with centres near $38^{\circ} \mathrm{N}$ and $34^{\circ} \mathrm{N}$.

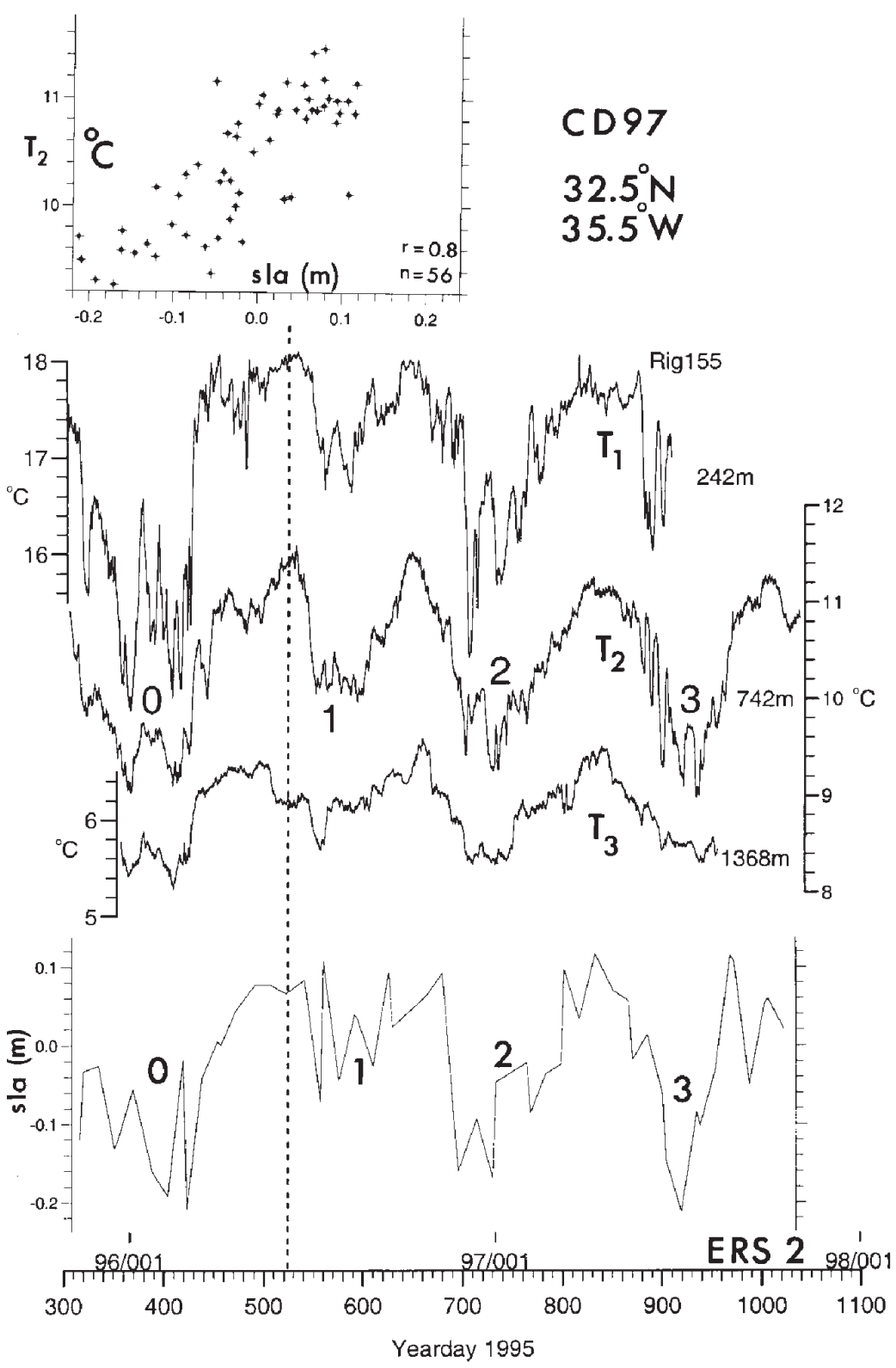

Figure 5. ERS 2 sla values (m) using passes 038,088 and 310 at $32.5^{\circ} \mathrm{N}$ (the latitude of Rig 155) over a 2-y period. Corresponding in situ temperature $\left({ }^{\circ} \mathrm{C}\right)$ records obtained on Rig 155 at the upper layer $(242 \mathrm{~m}), \mathrm{T}_{1}$, lower layer $(742 \mathrm{~m}), \mathrm{T}_{2}$, and deep layer $(1368 \mathrm{~m}), \mathrm{T}_{3}$. Note the temperature signal has a dominant near semi-annual component. Correlation plot of $\mathrm{T}_{2}$ against sla is shown above. Cooler near central regions of four Storm eddies moving westward past Rig 155 are shown by $0,1,2,3$ and are associated with low sla values. Dashed line corresponds to HMS 'Hecla' passing the rig position in June 1996 (see Figure 8). 
The correlation between altimeter sla data and SST anomalies will be low in this region with respect to the dynamic correlation below the seasonal thermocline since the altimeter measures both heat flux and dynamic responses. Although the mooring rig did not provide a SST record, SST data were extracted for the rig positions from COADS data (Slutz et al., 1985; Woodruff, 2001) to provide SST, or $\mathrm{T}_{0}$ values. Again, the annual signal was removed to give a SST anomaly which was then correlated with sla, with the annual signal removed, so that the in situ temperature measurement correlation values could be extended to the sea surface.

\section{RESULTS AND OBSERVATIONS}

\section{Remote sensing of internal temperature oscillations}

There is a clear correspondence between in situ temperature and sla even though the resolution in time for the sla data does not reveal all the detailed temperature structure. The sla results together with the temperature records (Figure 5) show four cyclonic eddies or storms passing Rig 155 during the 2-y measurements period. This is seen particularly clearly for the temperature record in the permanent thermocline (at $742 \mathrm{~m}$ ) or lower layer with temperature $\mathrm{T}_{2}$, where the temperature ranges between $\sim 9^{\circ} \mathrm{C}$ and $\sim 11{ }^{\circ} \mathrm{C}$ with semi-annual periodicity. Similar semi-annual structures are seen in the altimeter sla data which range from -20 to $+10 \mathrm{~cm}$, giving a simple ratio relationship of $\sim 15 \mathrm{~cm}\left({ }^{\circ} \mathrm{C}\right)^{-1}$ at $742 \mathrm{~m}$ depth.

The results for the upper layer (at $242 \mathrm{~m}$ ) temperature, $\mathrm{T}_{1}$, gave the following numerical (i.e. using the dimensions given) linear regression with $s l a=a=\tilde{\mathrm{a}}+\dot{a}$,

$\mathrm{T}_{1}\left({ }^{\circ} \mathrm{C}\right)=7.57 \operatorname{sla}(\mathrm{m})+17.1$

The temperature gradient at $242 \mathrm{~m}$ is such that a change of $1^{\circ} \mathrm{C}$ is equivalent to an isotherm displacement of $88 \mathrm{~m}$ (see Pingree \& Sinha (2001) for CTDs in the region where mean temperature gradients were estimated) and when sla $=0, \mathrm{~T}_{1}=17.1^{\circ} \mathrm{C}$ and the mean temperature at $242 \mathrm{~m}$ for these 44 observations is $17.0^{\circ} \mathrm{C}$ with mean sla defined as $\tilde{a}=0.0145 \mathrm{~m}$. Hence we can rewrite eqn 3 in terms of isotherm displacement as

Depth of $17.0^{\circ} \mathrm{C}$ isotherm $(\mathrm{m})=666 a \dot{a}(\mathrm{~m})+242 \mathrm{~m}$

where $\dot{a}$ is the fluctuating component of sla over the measurement period. The standard deviation of temperature for the upper layer at $242 \mathrm{~m}$ depth over a $\sim 2$-y period was $0.91^{\circ} \mathrm{C}$, so the isotherms have a vertical displacement standard deviation of $\sim 80 \mathrm{~m}$ at this level. The $\sim 2$ y (607 days) mean temperature at $242 \mathrm{~m}$ was $17.0^{\circ} \mathrm{C}$.

The results for the lower layer temperature, $\mathrm{T}_{2}$, gave the following numerical regression with sla,

$\mathrm{T}_{2}\left({ }^{\circ} \mathrm{G}\right)=5.44 a(\mathrm{~m})+10.5$
For the lower layer at $742 \mathrm{~m}$, a change of $1^{\circ} \mathrm{C}$ is equivalent to an isotherm displacement of $116 \mathrm{~m}$ and when $a=0$, $\mathrm{T}_{2}=10.5^{\circ} \mathrm{C}$ and the mean temperature at $742 \mathrm{~m}$ for these 56 observations is $10.4^{\circ} \mathrm{C}$. Eqn 5 can be rewritten as

Depth of $10.4^{\circ} \mathrm{C}$ isotherm $(\mathrm{m})=631 \dot{a}(\mathrm{~m})+742 \mathrm{~m}$

The standard deviation of temperature at this level was $0.65^{\circ} \mathrm{C}$ over the 2 -y record period so the isotherms in the permanent thermocline have a displacement standard deviation of $\sim 75 \mathrm{~m}$. The $2 \mathrm{y}$ (735 days) mean temperature at $742 \mathrm{~m}$ was $10.4^{\circ} \mathrm{C}$.

Eqns 4 and 6 form the basis of the statement (Pingree \& Sinha, 1998) that there is an inverted $\sim 650$ fold increase in the displacement of isotherms or magnification, B, with respect to the sla in this region. Longterm changes in $\mathrm{B}$ or climate changes would require repeat surveys but the effects of rapid climate changes in sla values on ocean circulation are considered in Pingree (2002).

From a monitoring or climate perspective, we need to know the degree to which changes in structure in the deep ocean interior or internal oscillations can be determined by remote sensing, i.e. how much of the variance in the in situ measurements can be explained or realized by measurements from space. This is effectively the square of the correlation $\left(r^{2}\right)$ between the variables considered. These squared values are listed in Table 1. Clearly a correlation of a variable with itself will give a correlation coefficient of 1 and values of $r^{2}=1$ can be seen along the diagonal in Table 1. Other relevant $r^{2}$ values are listed below this diagonal. The $r^{2}$ value for $\mathrm{T}_{1}$ against sla is $r^{2}=0.53$ for the $2-y$ period or said another way $53 \%$ of the variance in near surface temperature is explained by eqns 3 or 4 . For the lower level in the permanent thermocline, the altimeter data can explain $63 \%$ of the observed in situ variance in the temperature record, $\mathrm{T}_{2}$ (eqns $5 \& 6$ ). Using the passes individually resulted in a 5\% higher $r^{2}=0.66$ value for 088 than for passes 038 and 310 at $32.5^{\circ} \mathrm{N}$ which was the closest pass to the position of Rig 155 (see Figure 1). The standard error for the scatter of points (see Figure 5) about the regression line of eqn 5 is $\pm 5 \mathrm{~cm}$ or $\pm 0.37^{\circ} \mathrm{C}$.

We note that a correlation between $\mathrm{T}_{1}$ and $\mathrm{T}_{2}$ gives $r^{2}=0.77$ (Table 1), so there is still more correlation between $\mathrm{T}_{1}$ and $\mathrm{T}_{2}$ than between $\mathrm{T}_{2}$ and sla. For the deep level at $\sim 1400 \mathrm{~m}, r^{2}$ decreases to $r^{2}=0.56$, so the altimeter sla data best match displacements in the permanent thermocline near $742 \mathrm{~m}$ depth near $10^{\circ} \mathrm{C}$. The mean temperature at the deep level (over 602 days) was $6.1^{\circ} \mathrm{C}$ and the standard deviation of temperature was $0.37^{\circ} \mathrm{C}$, equivalent to a displacement standard deviation of $67 \mathrm{~m}$. Hence displacements of isopycnals or isotherms at $242 \mathrm{~m}, 742 \mathrm{~m}$ and $1368 \mathrm{~m}$ are comparable. Only near the surface are displacements relatively small resulting in little correlation of sla with SST anomalies.

The values above the diagonal in Table 1 give the ratio of the square root of the dimensional variance between the two variables considered with the number of

Figure 3. Annual signal of sea surface height (in mm) derived from altimeter data across the North Atlantic Ocean from $10^{\circ} \mathrm{W}-77^{\circ} \mathrm{W}$ at $32.5^{\circ} \mathrm{N}$ against Julian Day showing a generally zonally coherent seasonal signal of $\sim 5 \mathrm{~cm}$ amplitude with increasing amplitude in the west.

Figure 4. Annual signal of sea surface height (in mm) derived from altimeter data across the North Atlantic Ocean from $2^{\circ} \mathrm{S}-55^{\circ} \mathrm{N}$ at $35^{\circ} \mathrm{W}$ against Julian Day showing large regions $\left(10^{\circ} \mathrm{N}-15^{\circ} \mathrm{N}, 17^{\circ} \mathrm{N}-45^{\circ} \mathrm{N}\right)$ where the seasonal signal is coherent meridionally. In the region $17^{\circ} \mathrm{N}-45^{\circ} \mathrm{N}$, the amplitude is $\sim 5 \mathrm{~cm}$ with an increasing northward tendency to $50^{\circ} \mathrm{N}$. 

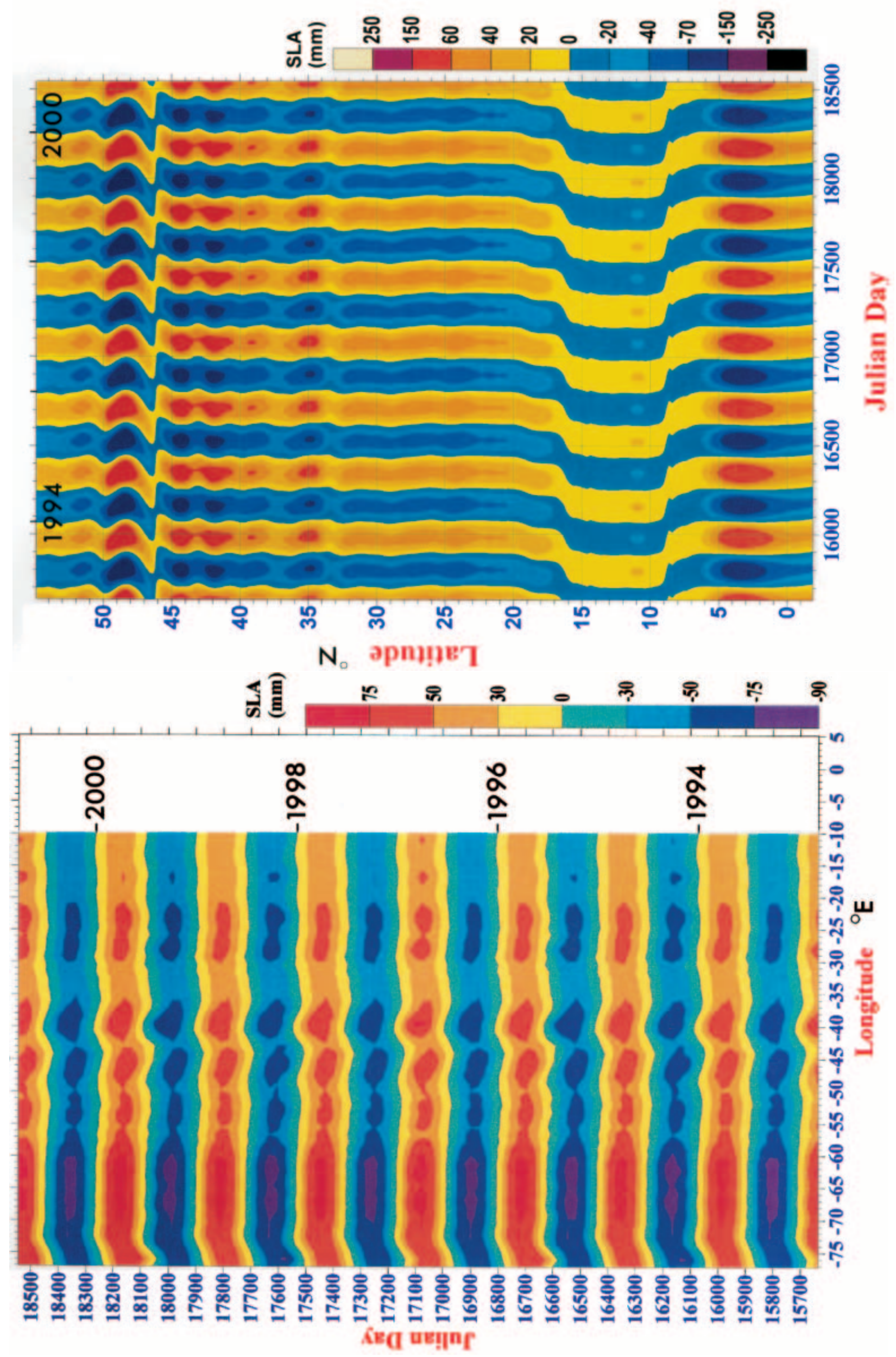


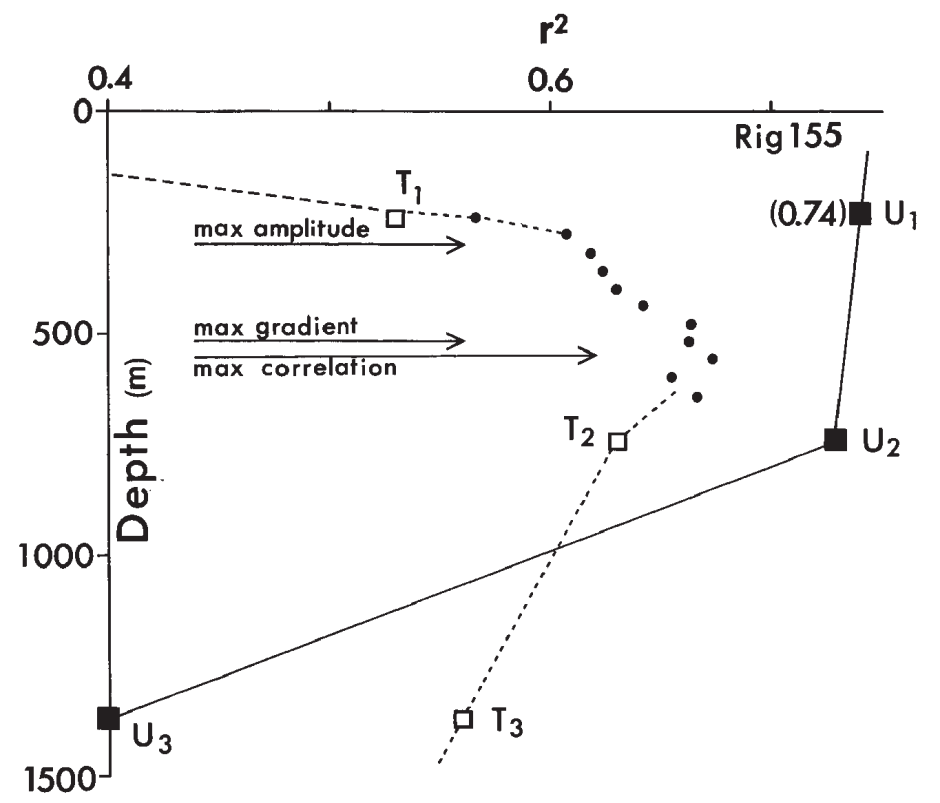

Figure 7. Summary diagram showing sla correlation $r^{2}$ structure for displacements (temperature) and currents at $32.5^{\circ} \mathrm{N}$ in the Subtropical North Atlantic. Solid squares are current meter values with maximum $r^{2}=0.74$ : open squares are temperature values at the current meter depths: the 11 dots are the thermistor chain temperature against sla correlation squared values with maximum $r^{2}=0.67$. At the sea surface $r^{2}=\sim 0.1$. Depths of maximum displacement of isotherms, maximum vertical temperature gradient and maximum correlation for temperature structure indicated.

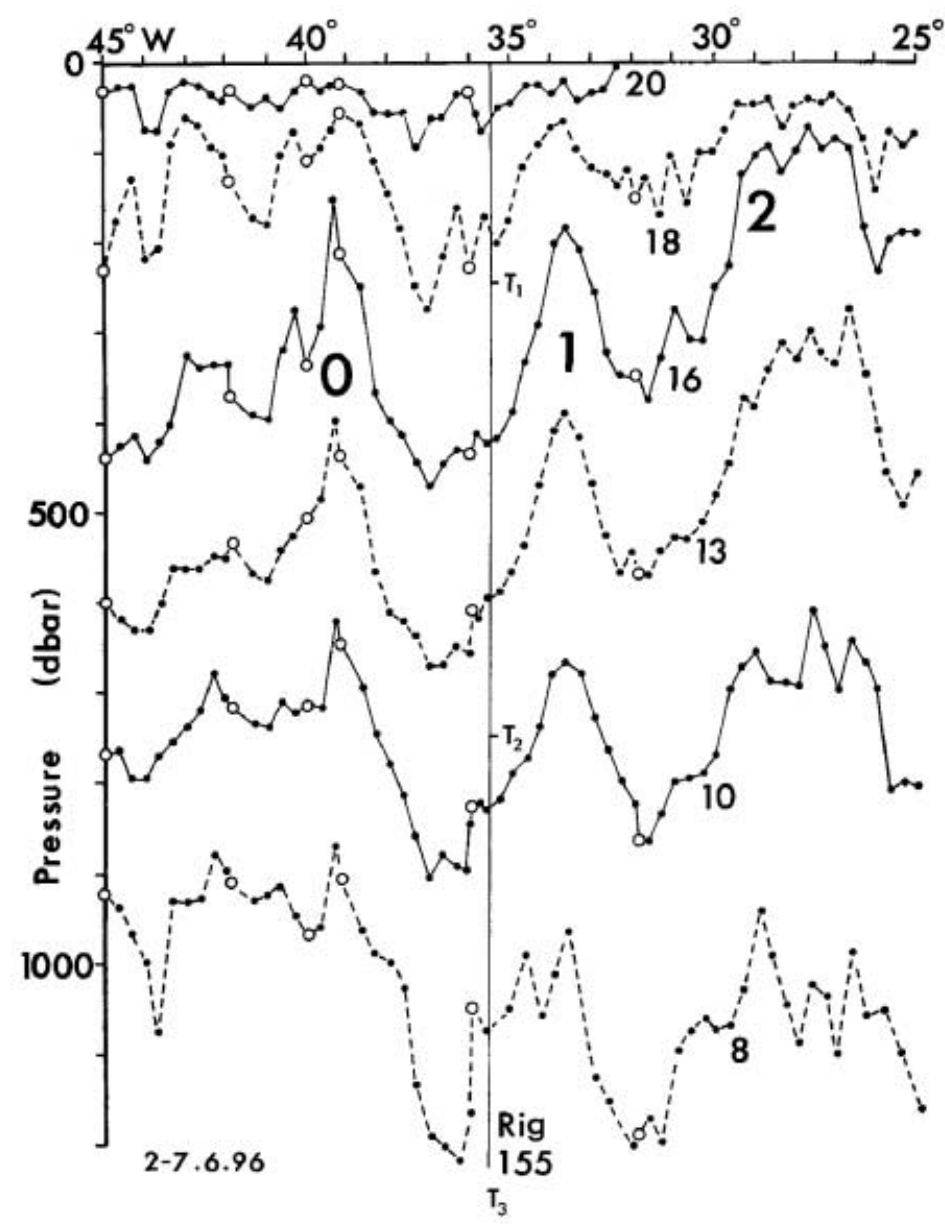

Figure 8. Part of HMS 'Hecla' XBT/CTD North Atlantic section near $32.5^{\circ} \mathrm{N}$, covering $\sim 2000 \mathrm{~km}$ from $2-7$ June 1996 , showing isotherms $\left({ }^{\circ} \mathrm{C}\right)$ from surface to $1200 \mathrm{dbar}(\sim 1188 \mathrm{~m})$ against longitude $\left({ }^{\circ} \mathrm{W}\right)$ showing wavelength structure in the permanent thermocline associated with the near semi-annual oscillations. Calibrated XBT/T5 data points shown as dots: CTD values open circles. Position of Rig 155 indicated by line (see Figure 6). Features numbered 0, 1 and 2 shown here in space are seen in time at the mooring position and in the ERS data (Figure 5). Near $30^{\circ} \mathrm{W}$, 'Hecla' moved northward and at $25^{\circ} \mathrm{W}$ was at $35^{\circ} \mathrm{N}$, so Storm 3 is not fully resolved. 


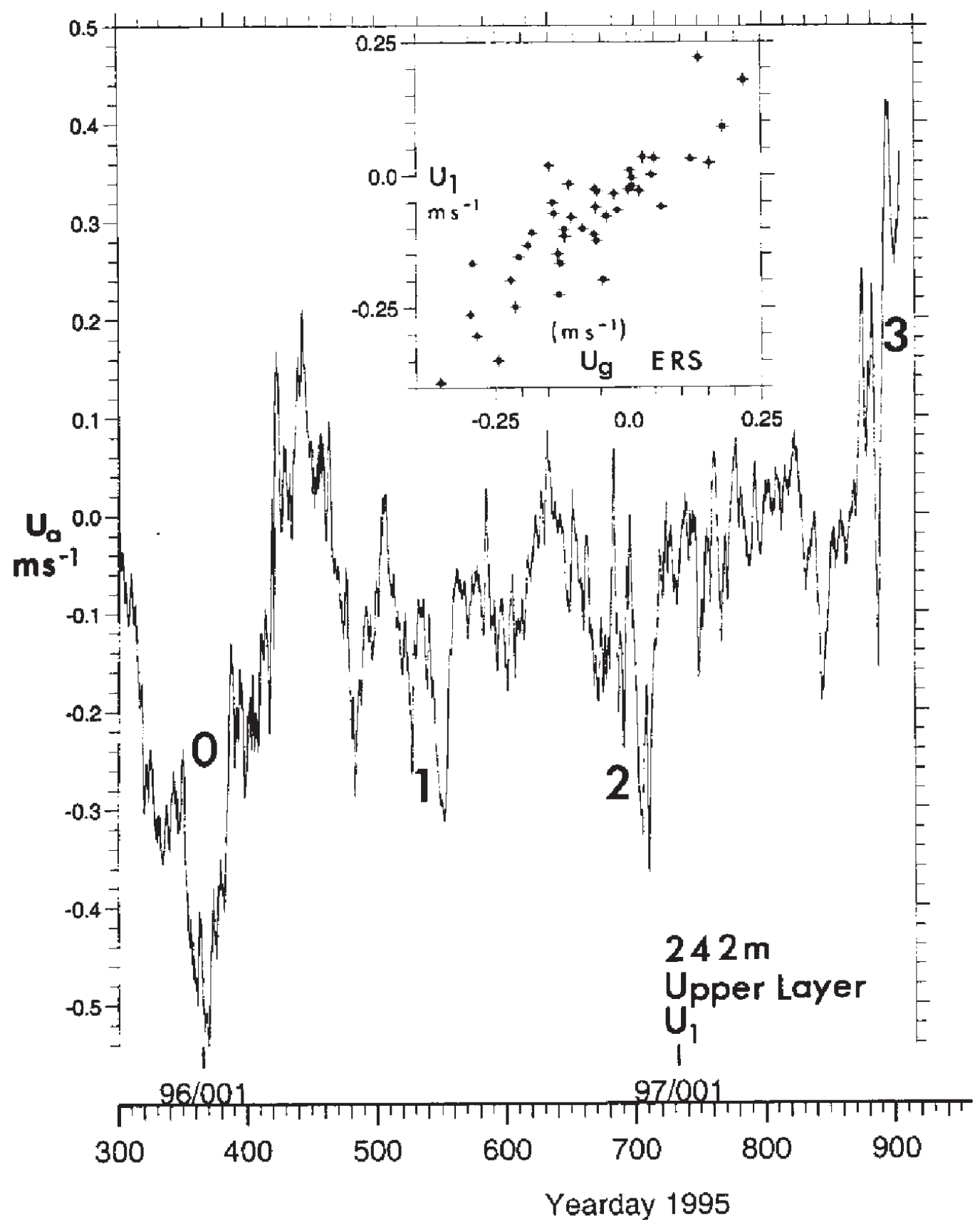

Figure 9. Measured upper layer current component $\left(\mathrm{m} \mathrm{s}^{-1}, 24 \mathrm{~h}\right.$ average at $242 \mathrm{~m}$ depth), $\mathrm{u}_{\mathrm{a}}$, normal to ascending orbit 088 showing semi-annual structure and correlation plot of $\mathrm{u}_{\mathrm{g}}$ derived from remote sensing altimeter data against upper layer currents, $\mathrm{U}_{1}$ in situ (both in $\mathrm{m} \mathrm{s}^{-1}$ ). Large scale current structures or Storms are indicated by 0, 1, 2 and 3 but the structures are more evident in integrated properties, e.g. displacement (Figure 5).

observations given in parentheses below. The dimensional variance is the variance converted to the same units or dimensions and the square root is the standard deviation, SD. This ratio or scale factor is seen to be 1.6 for $\mathrm{T}_{1}$ and $\mathrm{T}_{2}$ using 2420 in situ values. Thus the temperature standard deviation at $242 \mathrm{~m}$ was $1.6 \times$ the temperature standard deviation at $742 \mathrm{~m}$ for the common data period $(\sim 2 \mathrm{y})$. In terms of isotherm displacement, the displacement at the upper layer is $\sim 1.2 \times$ the lower layer. Isotherm depth variation determined from the root of the variance at $242 \mathrm{~m}$ was $920 \times$ that determined from the SD of sla; isotherm depth SD at $742 \mathrm{~m}$ was $795 \times$ the SD of sla. These results could be interpreted as showing that the magnification of displacement was $\mathrm{B} \sim 850 \times$ sla rather than $650 \times$. This definition of magnification, $\mathrm{B}$, takes no account of lack of correlation or error in measured variables.

With oceanographic data for the region, it is a simple matter to convert the $10.4^{\circ} \mathrm{C}$ isotherm eqn 6 to a more convenient one, the $10^{\circ} \mathrm{C}$ isotherm, for example, and sometimes taken to represent the permanent thermocline.

Depth of $10^{\circ} \mathrm{C}$ isotherm $(\mathrm{m})=631 a ́(\mathrm{~m})+788 \mathrm{~m}$

Overall, these results for temperature show that we can interpret maps of sla (see figure 16 of Pingree et al., 1999, 


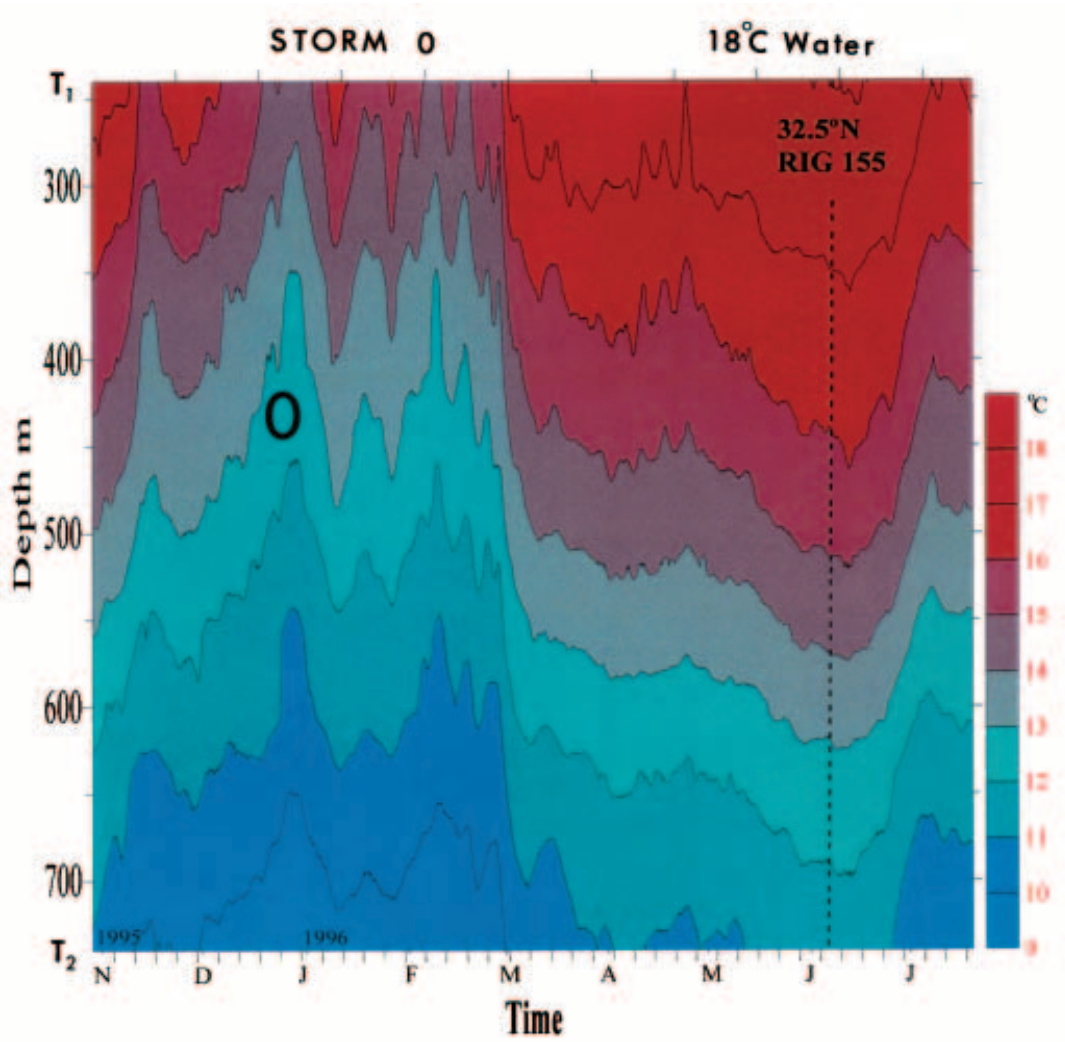

Figure 6. The 265 day thermistor chain record from Rig 155 showing near semi-annual isotherm displacements in the permanent thermocline (from $240 \mathrm{~m}, \sim \mathrm{T}_{1}$, to $740 \mathrm{~m}, \sim \mathrm{T}_{2}$ ) at $32.5^{\circ} \mathrm{N} 35.5^{\circ} \mathrm{W}$ from end of October 1995 to mid-July (J) 1996. First day of the month (denoted by single letter) indicated. The start of data in time matches the end of the SeaSoar data along $32.5^{\circ} \mathrm{N}($ Figure 2 ). Storm 0 (indicated by ' 0 ') is seen to pass near Rig 155 (maximum cooling with raised isotherms) in January (J) and February (F) 1996; warm subtropical conditions $\left(18^{\circ} \mathrm{C}\right.$ Water above $\left.240 \mathrm{~m}\right)$ prevail from March to July 1996. Dashed line in early June corresponds in space and time with continuous line in Figure 8.

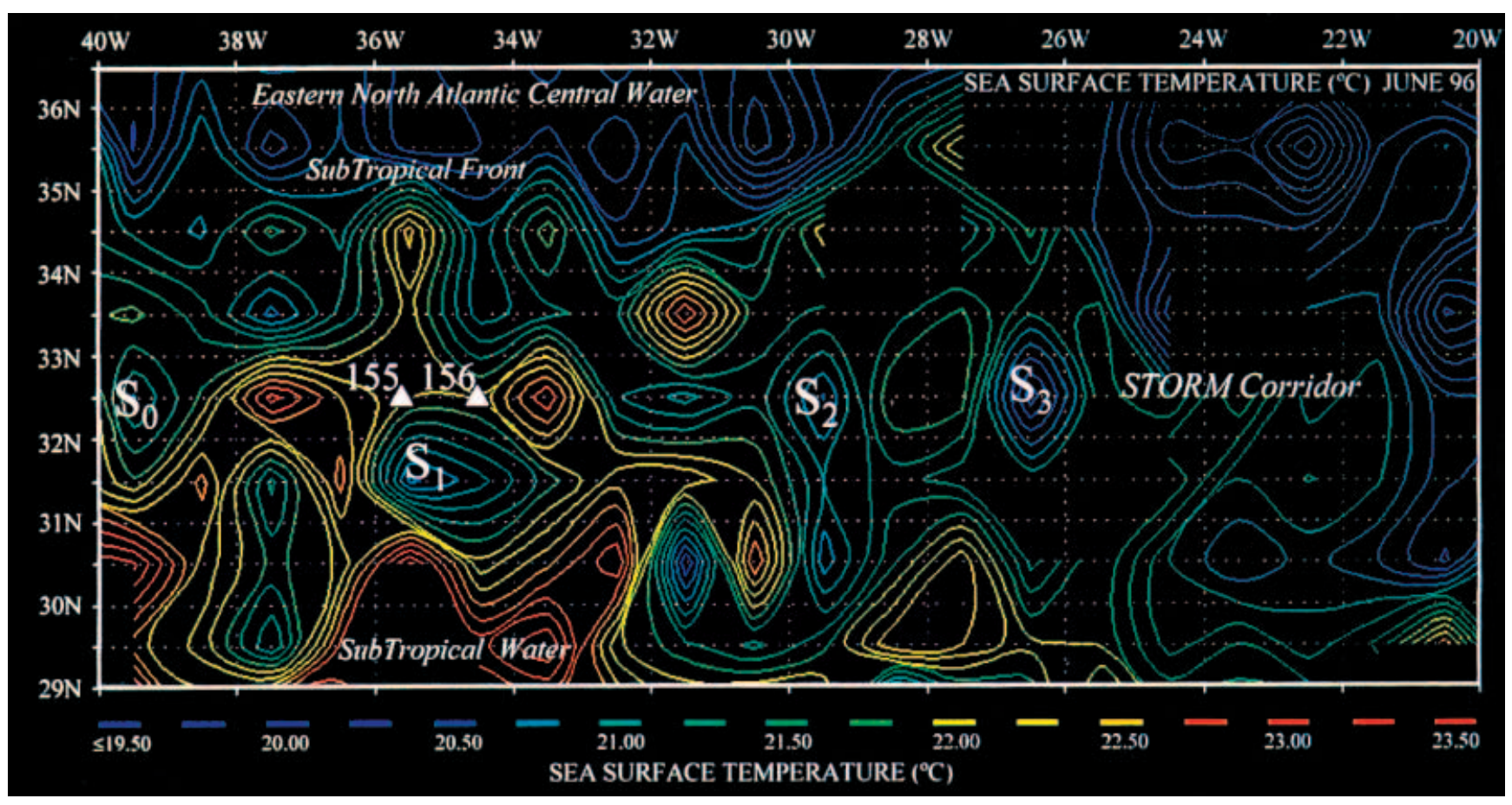

Figure 11. Sea surface temperature (SST) south of the Subtropical Front/Azores Current near $35^{\circ} \mathrm{N}$ showing the position of four Storm eddies (S0, S1, S2, S3) that passed near the position of moorings 155 and 156 during the 2-y deployment period (starting end of October 1995). The June period shown corresponds to the North Atlantic crossing of HMS 'Hecla' along $32.5^{\circ} \mathrm{N}$ in June 1996 that identified upward doming of isotherms (S0, S1, S2, Figure 8) which are seen to have a cool SST signature. The SST cooling for $\mathrm{S} 1$ was not found in the 'Hecla' section as it can be seen that this eddy was south of the ship's track and mooring positions at $32.5^{\circ} \mathrm{N}$ (see also Pingree \& Sinha, 2001). 

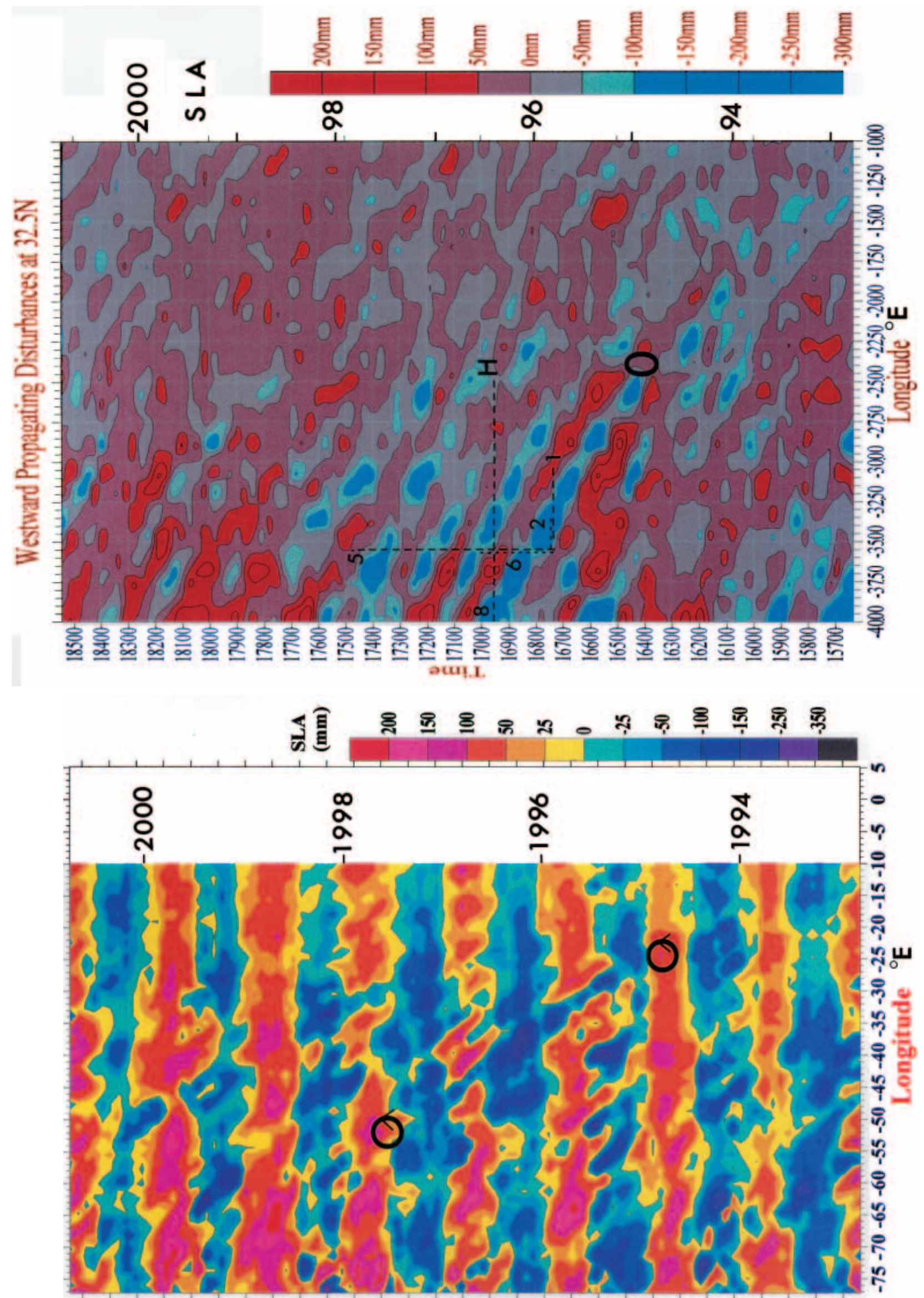

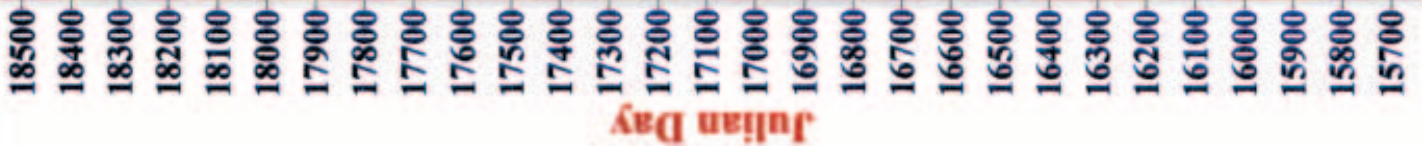




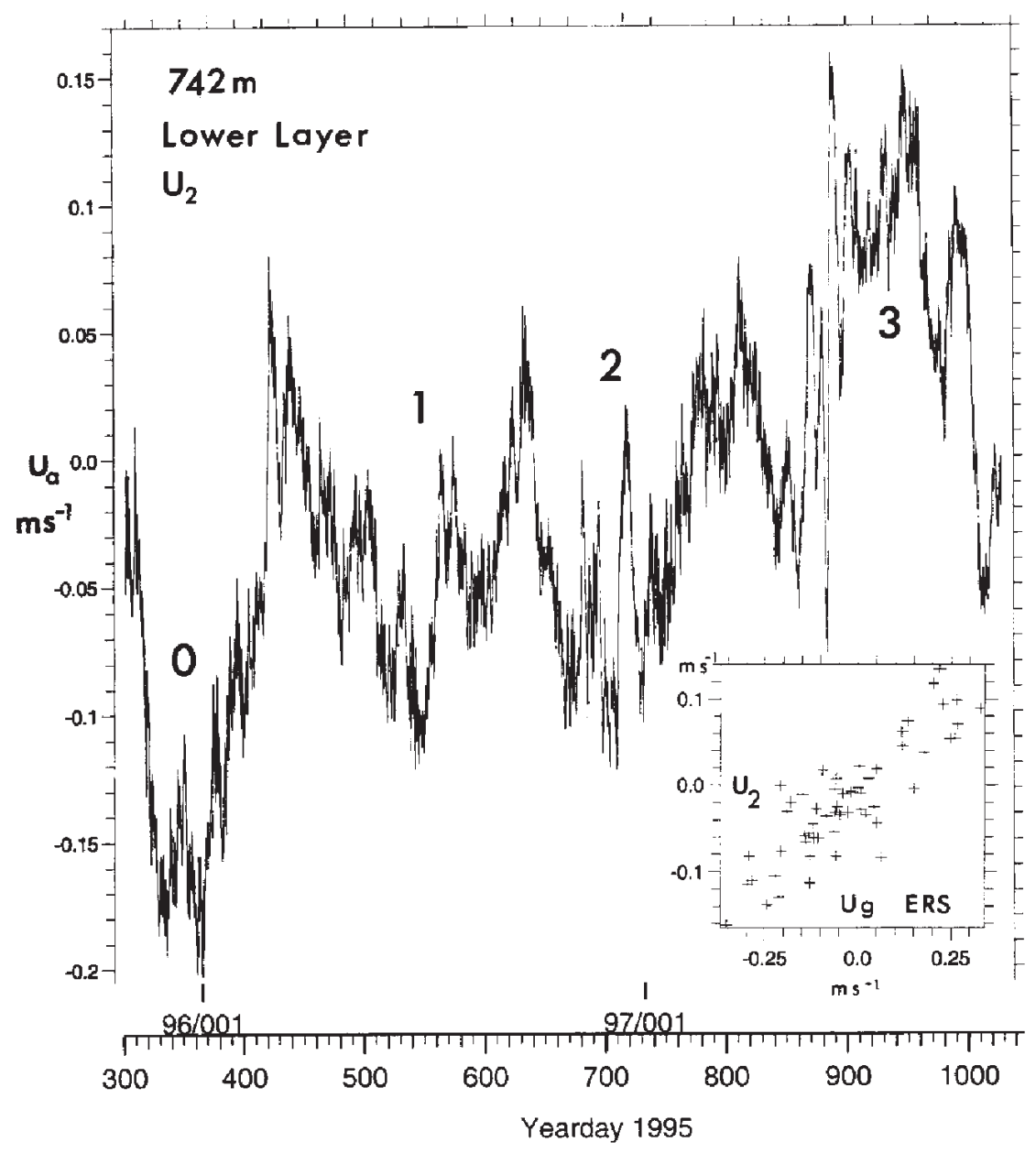

Figure 10. Lower layer in situ current component $\left(\mathrm{m} \mathrm{s}^{-1}, 24 \mathrm{~h}\right.$ average, at $742 \mathrm{~m}$ depth), $\mathrm{u}_{\mathrm{a}}$, normal to ascending orbit 088 and correlation plot of $\mathrm{u}_{\mathrm{g}}$ derived from remote sensing altimeter data against $\mathrm{U}_{2}$ in situ (both in $\mathrm{m} \mathrm{s}^{-1}$ ). Eddy structures $0,1,2$ and 3 indicated. Structure ' 3 ' is cusped toward positive values (and near east component) since the centre of this westward propagating cyclonic eddy passed to the north of the rig position. This slightly variable latitude position for the eddy centre makes the east current component appear less semi-annual than the north component or the temperature signal (Figure 5).

for example) as mirroring the internal structure of the ocean which shows a $\sim 650 \times$ magnification of the sla in the region considered. Of course, the sla is not going to represent all the internal structure, for example, a deep meddy (see Richardson et al., (2000) for some meddy tracks in the region) with a small or variable vertical attenuation scale giving little or variable sea surface temperature or current signature. At present, there is no complete remote sensing substitute for in situ measurements at depth. The results for isotherm displacement show a maximum correlation between in situ temperature and sla at the $742 \mathrm{~m}$ depth level and nonlinearity between variables (e.g. temperature and depth; temperature at one level with temperature at another e.g. $\mathrm{T}_{1}$ and $\mathrm{T}_{2}$ ) accounts for some loss of correlation between the variables. Improvements of sla correlation with temperature could be made by taking into account nonlinearity but clearly correlation with near SST (or density) anomalies will be relatively small (see Figure 2), except in a heat content sense. Annual signals of sla and SST will correlate; they are merely phase shifted with the sla maximum coming at the end of the heating cycle or at the end of September in the region considered (Figures 3 or 4 ).

A more accurate estimate for the level for maximum temperature correlations can be determined using the thermistor chain temperature record on Rig 155. The $400 \mathrm{~m}$ long thermistor chain on Rig 155 spanned the water column between the upper and lower layer with 11 sensors spread evenly within the depth range $\sim 243-643 \mathrm{~m}$. The thermistor chain record worked well for $\sim 9$ months which gives 21 sla values for correlations at the level of each thermistor. The results (Figure 6) show little squeezing

Figure 12. Sea surface height (in mm) derived from altimeter data across the North Atlantic Ocean from $10^{\circ} \mathrm{W}-77^{\circ} \mathrm{W}$ at $32.5^{\circ} \mathrm{N}$ against Julian Day showing near semi-annual propagating and non-propagating (annual, see Figure 3) structure over an 8-y period. The most conspicuous westward tracking depression is located between the two Os. This is Storm 0 (with arrows showing cyclonic vorticity) with an apparent travel curve of $\sim 750$ days. Figure 13. Summary diagram showing near semi-annual westward propagating disturbances at $32.5^{\circ} \mathrm{N}$ detected by altimeter, from $10^{\circ} \mathrm{W}$ to $40^{\circ} \mathrm{W}$ over an 8-y period ( Julian Days, JD). The altimeter signal is the sla $(\mathrm{mm})$ with the annual signal removed and the dominant period is near 200 days. The dashed lines numbered 1, 2, 5, 6 and 8 depict the time and distance lines for the measurements shown in Figures 1, 2, 5, 6 \& 8 . Drogued buoys and ALACE floats tracked along the sla travel curve of Storm 0 which has an origin near $25^{\circ} \mathrm{W}$ (marked ' 0 ') near JD 16400 . Storm 0 was surveyed by RRS 'Charles Darwin' near $33^{\circ} \mathrm{W}$ (Figure 1) about $\sim 325$ days later (JD 16725) and intercepted by HMS 'Hecla' (H) 550 days later $($ JD 16950$)$ near $40^{\circ} \mathrm{W}$ (Figure 8). 
and stretching of isotherm separation thickness in this depth range (cf. Figure 2) and give similar mean temperature gradients that were determined from CTD profiles in the region. The correlation results (Figure 7) give a maximum value of $r^{2}=0.67$ at a depth of $560 \mathrm{~m}$. The depth of the maximum temperature gradient in the region between $30^{\circ}-40^{\circ} \mathrm{W}$ at $32.5^{\circ} \mathrm{N}$ was determined as $\sim 530 \mathrm{~m}$ based on CTDs and XBTs in the region (HMS 'Hecla' North Atlantic section, Pingree \& Sinha, 1998). The thermistor chain data gave a depth of $\sim 520 \mathrm{~m}$ for the maximum temperature gradient. This value represents a mean value over 265 days where the isotherms are elevated (due to the passage of Storm 0) and then depressed (subtropical water or anticyclonic structure).

The maximum displacement of isotherms was determined by measuring the temperature changes at each level and relating these values with the local mean temperature gradient. Isopycnal displacements can also be estimated by eye (see Figure 6). The maximum displacement of isotherms occurred at $\sim 330 \mathrm{~m}$ ( $\sim 300 \mathrm{~m}$ peak to trough displacement) but changes in displacement amplitude with depth were only $\sim \pm 15 \%$ of the mean $(265 \mathrm{~m})$ in the depth range $240-740 \mathrm{~m}$. There is no accepted definition for the depth of the permanent thermocline but the region of maximum temperature gradient near $500 \mathrm{~m}$ depth rather than the depth of the $10^{\circ} \mathrm{C}$ isotherm gave the highest correlation between sla and temperature.

\section{Zonal changes in temperature structure}

Changes in temperature against longitude at the latitude $32.5^{\circ} \mathrm{N}$ (Figure 8) were obtained from CTD and XBT profiles conducted during HMS 'Hecla's North Atlantic crossing in June 1996. This calibrated $2000 \mathrm{~km}$ section shows comparable maximum displacement of isotherms $(\sim 250-300 \mathrm{~m})$ in the depth range $300 \mathrm{~m}$ to $1200 \mathrm{~m}$, which rapidly decrease in amplitude near the surface or in the euphotic zone. Storm 0 has now passed the mooring rig and is near $40^{\circ} \mathrm{W}$; Storm 1 has yet to arrive (see Figure 5). The general shallowing of isotherms above the $10^{\circ} \mathrm{C}$ isotherm to the east reflects the southward flow of the Subtropical Gyre in the Eastern Basin but not subduction through the Subtropical Front or Azores Current. The southward geostrophic transport between $50^{\circ} \mathrm{W}$ and $20^{\circ} \mathrm{W}$ was $24 \mathrm{~Sv}$ (2000 dbar reference level). The thickness of the $18^{\circ} \mathrm{C}$ Water increased in the Western Basin, where water in the temperature $\left(\mathrm{T},{ }^{\circ} \mathrm{C}\right)$ range $17.4<\mathrm{T}<18.3$ or density $\left(\sigma_{\mathrm{o}}\right)$ range $26.4<\sigma_{\mathrm{o}}<26.5$ had a maximum thickness of $550 \mathrm{~m}$ $\left(125 \mathrm{~m}\right.$ to $675 \mathrm{~m}$ depth, cf. Figure 2) near $65^{\circ} \mathrm{W}\left(34^{\circ} \mathrm{N}\right)$ where Subtropical Mode Water or Sargasso Sea Mode Water forms (New et al., 2001).

The SeaSoar section (Figure 2) showed that the water near $\sigma_{\mathrm{o}}=26.5$ or between isopycnals in the density band $26.4<\sigma_{\mathrm{o}}<26.6$ squeezed from $130 \mathrm{~m}$ vertical extent to only $20 \mathrm{~m}$ thick over the centre of Storm 0. This maximum $\sim 7$ fold increase of potential vorticity in this density band where the isopycnals are raised (to $\sim 130$ dbar) over Storm 0 restricts the isentropic movement or exchange of water along isopycnals, thus tending to preserve the anomaly, guaranteeing its survival. This effect is still evident in the HMS 'Hecla' section about 250 days later where the squeezing or increase in potential vorticity in the same density range is locally increased at the centre of Storm 0, but is now reduced to only a $\sim 3$ fold increase with respect to background or external conditions. An important aspect of the structure is that below the seasonal thermocline the crests are more upward penetrating than the troughs. This effect is also seen in time in the thermistor chain record (Figure 6, near the $13^{\circ} \mathrm{C}$ isotherm for example).

\section{Remote sensing of deep ocean currents}

The measured in situ upper layer currents, $\mathrm{U}_{1}$, normal to an ascending pass, $\mathrm{u}_{\mathrm{a}}$, were derived as described in Methods and the current amplitudes for the upper layer $(242 \mathrm{~m})$ (Figure 9) show some semi-annual periodicity. Even after applying a $24 \mathrm{~h}$ average to the in situ measurement, it can be seen that altimeter current interpolations derived from two spot values 35 days apart (or even $\sim 2$ days apart) are unlikely to represent a measured current at the interpolated time. The altimeter $u_{g}$ values (with no interpolations in time) for all passes (038, 088 and 310) were plotted against the appropriate current meter values $\left(\mathrm{u}_{\mathrm{a}}\right.$ or $\left.\mathrm{u}_{\mathrm{d}}\right)$ and the results give the regression equation

$\mathrm{U}_{1}\left(\mathrm{~cm} \mathrm{~s}^{-1}\right)=0.80 \mathrm{u}_{\mathrm{g}}-2.3$

For the lower level (Figure 10) in the permanent thermocline the semi-annual structure is more evident and the resulting corresponding regression equation is

$\mathrm{U}_{2}\left(\mathrm{~cm} \mathrm{~s}^{-1}\right)=0.35 \mathrm{u}_{\mathrm{g}}-0.9$

The low values for the constants shows that mean barotropic and baroclinic Eulerian currents in the study region are relatively small since the current meter measures the mean but the mean sla is removed (in the absence of a well defined geoid) in the methods. The $r^{2}$ values are $r^{2}=0.74$ for eqn 8 and $r^{2}=0.73$ for eqn 9 , both larger than the corresponding temperature values (Table 1) as anticipated. At the deep level $r^{2}=0.40$, so in the case of currents, the maximum correlation occurs near the upper levels rather than in the permanent thermocline. This is to be expected since the altimeter current measurement is a sea surface gradient. The variance in altimeter $\mathrm{u}_{\mathrm{g}}$ is $1.1 \times$ the measured surface layer current variance. The scale factor for the ratio of standard deviations is $2.5 \times$ for currents in the permanent thermocline $(742 \mathrm{~m})$ where the measured values are weaker. The $r^{2}$ value for $\mathrm{U}_{1}$ against $\mathrm{U}_{2}$ is 0.80 . The ratio of measured or in situ current variance depends marginally on which component is being considered. This is why two values are given in Table 1 for the ratio of the in situ $\mathrm{SD}$ of $\mathrm{U}_{1}$ divided by the $\mathrm{SD}$ of $\mathrm{U}_{2}$. The $\mathrm{SD}$ ratio of 2.6 refers to the east component and the ratio of 2.0 to the north component of the upper current meter value with respect to the lower current meter value. This shows that the currents are weaker at depth as expected but the north component is less rapidly attenuated at this deeper level than the east component. This distortion of structure with depth is reflected in the data by a more rapid attenuation of the strongest westward currents at the lower level in the permanent thermocline. The standard deviation for east component of current $u$ in the upper layer (607 day record) was $14.3 \mathrm{~cm} \mathrm{~s}^{-1}$; the standard deviation for the north component was $16.6 \mathrm{~cm} \mathrm{~s}^{-1}$. For the deep level, the in situ current correlation with altimeter values falls to $r^{2}=0.40$. This low value is also reflected in the lower correlation of in situ data at this deep level $\left(\mathrm{U}_{3}\right)$ with the upper 
level $\left(\mathrm{U}_{1}\right)$ giving values of $r^{2}=0.36$ for the east component and $r^{2}=0.63$ for the north component (Table 1). The loss of correlation or decoupling between surface currents and deep currents results in low correlations between deep currents and altimeter derived values. For a Rossby Wave mode 1 structure we might expect to find inverse correlations between surface and deep currents below $\sim 1200 \mathrm{~m}$ (Pingree \& Sinha, 2001) but this was not found.

Finally, we note that the scatter of points about the upper layer regression line (eqn 8, Figure 9) has a standard error of $6 \mathrm{~cm} \mathrm{~s}^{-1}$ and so we can assert with $95 \%$ confidence that a single estimate using eqn 8 will be within $\pm 12 \mathrm{~cm} \mathrm{~s}^{-1}$ of its measured value. The inherent noise in the altimeter measurements did not show that the predicted results for pass 088 (which was closest to the mooring position) were significantly better than the results for passes 310 or 38 .

\section{Significance of the magnification, $B$, result}

The ratio of surface displacement to the displacement of the thermocline relates to vertical decay scale for geostrophic currents and tells us about the vertical structure for temperature and currents in the ocean. Assume a simple baroclinic model with separated time $(\mathrm{t})$ and depth $(\mathrm{z})$ variables and the north component of geostrophic current defined as $\mathrm{v}_{\mathrm{i}}(\mathrm{z}, \mathrm{t})=\mathrm{v}_{\mathrm{i} 0}(\mathrm{t}) \mathrm{e}^{-z / b}$ where $\mathrm{z}$ is depth downwards and $b$ is the attenuation scale. Differentiating eqn 1 with respect to $\mathrm{z}$ and substituting for $\mathrm{dv}_{\mathrm{i}} / \mathrm{dz}$ and $\mathrm{v}_{\mathrm{i}}$ gives

$b \mathrm{v}_{\mathrm{i} 0}=\mathrm{v}_{\mathrm{i}}\left(\mathrm{g} / \mathrm{N}^{2}\right) /(\mathrm{B})$

where $\mathrm{B}$ is the magnification or ratio of the displacement of the permanent thermocline to the displacement of the sea surface and $\mathrm{N}$ is the Brunt-Vaisala Frequency, $\mathrm{N}^{2}=$ $\mathrm{g} / \rho(\mathrm{d} \rho / \mathrm{dz})_{\mathrm{p}}$, where $\rho$ is density and p pressure. $\mathrm{g} / \mathrm{N}^{2}$ is the barotropic scale for horizontal currents in a stratified fluid. For $\mathrm{z} / \mathrm{b} \ll 1$, near the surface or relatively large $b$ with barotropic response in the upper layer, B can be interpreted as the ratio of barotropic to baroclinic decay scales. In the special case where the decay scale for potential density gradient or $\mathrm{N}^{2}(\mathrm{z})$ is the same as for currents, then the value of $\mathrm{B}$ is constant with depth, with $\mathrm{B}=$ $\left(\mathrm{g} / \mathrm{N}^{2}(0)\right) / \mathrm{b}$. In fact, it is only required that currents and potential density have the same structure function with depth for B to be constant. If the surface currents are also attenuated to zero near the sea-floor, then $\mathrm{B}=\rho / \delta \rho$ where $\delta \rho$ is the potential density difference between surface and bottom. Take for example CTD 7023 at $32.5^{\circ} \mathrm{N} 36^{\circ} \mathrm{W}$ for the 'Hecla' section (Figure 8), below the seasonal thermocline at $\sim 200 \mathrm{~m}, \sigma_{0}=26.41 \mathrm{~kg} \mathrm{~m}^{-3}$ and at $3000 \mathrm{~m} \sigma_{0}=$ $27.85 \mathrm{~kg} \mathrm{~m}^{-3}$ which gives $\mathrm{B} \sim 700$, remarkably close to the value based on measurement. The resulting structure functions for current and displacement are not those expected for Rossby Wave propagation.

Values can be substituted into eqn 10 for an estimate of $b$ in the permanent thermocline. Between the depths of $\mathrm{T}_{1}$ and $\mathrm{T}_{2} \sim$ at $500 \mathrm{~m}$ depth were maximum correlation was found (Figure 7 ), the magnification was $\sim 650$. The origin of $\mathrm{z}=0$ is taken as the level of $\mathrm{T}_{1}$ or below the thermocline or mixed layer where the current structure decays with depth. The mean value of $\mathrm{N}$ in the $\sim 500 \mathrm{~m}$ depth interval between $\mathrm{T}_{1}$ and $\mathrm{T}_{2}$ was $\mathrm{N}=0.0039 \mathrm{~s}^{-1}$ ( $\sim 2.25$ cph buoyancy frequency, figure 23 of Pingree \&
Sinha (2001)) which gives $b \sim 700 \mathrm{~m}$. This value of $b$ shows that the current falls to 0.37 of its value over a vertical interval of $\sim 700 \mathrm{~m}$ comparable to a decay of $\mathrm{v}_{2}$ / $\mathrm{v}_{1} \sim 0.5$ over an interval of $\sim 500 \mathrm{~m}$ found by measurement (Table 1). Whilst $\mathrm{N}$ is fairly constant in this depth range with buoyancy frequency $\sim 2.2 \mathrm{cph}$ at $1000 \mathrm{~m}$ depth, below $1000 \mathrm{~m}$ depth, $\mathrm{N}$ has a decay scale of $\sim 850 \mathrm{~m}$ with a buoyancy frequency of $\sim 0.8 \mathrm{cph}$ at $1850 \mathrm{~m}$ depth.

Developing further for a barotropic current influence on the correlations or a further current component with a larger decay scale than $b$, then the total current, $\mathrm{v}(\mathrm{z})$, is defined as $\mathrm{v}(\mathrm{z})=\mathrm{v}_{\mathrm{o}}+\mathrm{v}_{\mathrm{i}}(\mathrm{z})$, where $\mathrm{v}_{\mathrm{o}}$ is constant with depth in a depth region of interest and $v_{i}$ is defined as before with near surface value of $\mathrm{v}_{\mathrm{i} 0}$ and a value tending to zero at $z / b \gg 1$. The reference level for $z=0$ is again taken at the base of the seasonal thermocline. Then with $\mathrm{v}_{\mathrm{o}} / \mathrm{v}_{\mathrm{i}}(0)=\mathrm{R}$ we get

$\mathrm{B}(\mathrm{R}+\mathrm{l})=\left(\mathrm{g} / \mathrm{N}^{2}\right) /\left(b \mathrm{e}^{z / b}\right)$

Eqn 11 can be compared with the temperature correlation or regression equations, eqns 4 or 6 for example. If $\mathrm{R}$ is fixed or constant, with $\mathrm{v}_{\mathrm{o}}$ and $\mathrm{v}_{\mathrm{i} 0}$ correlated or proportional, then a barotropic component will not affect the correlation between altimeter and isotherm displacement. If $\mathrm{v}_{\mathrm{o}}$ and $\mathrm{v}_{\mathrm{i} 0}$ are uncorrelated, then correlations of altimeter data with surface currents will be higher than correlations of altimeter data with upper layer isotherm displacement, since the isotherms do not respond to time variations of the barotropic component $\mathrm{v}_{\mathrm{O}}$.

The corresponding equation relating surface currents or altimeter derived slope values $(\theta)$ with in situ geostrophic currents, $\mathrm{v}(\mathrm{z}, \mathrm{t})$, is

$\mathrm{v}(\mathrm{z}, \mathrm{t})=\mathrm{m} \theta(\mathrm{t}) \mathrm{g} / \mathrm{f}+\mathrm{c}$

where $\mathrm{m}(\mathrm{z})$ and $\mathrm{c}(\mathrm{z})$ are constant in time and $\mathrm{m}(0)=1$ at the sea surface, see eqn 1 . Rewriting eqn 12 in terms of a two component model with a relatively large decay scale, or barotropic response, and a relatively small decay scale, $b$, for geostrophic current, gives

$\mathrm{v}(\mathrm{z})=\mathrm{v}_{\mathrm{o}}+\mathrm{v}_{\mathrm{i}}(\mathrm{z})=\mathrm{m}\left(\mathrm{v}_{\mathrm{o}}+\mathrm{v}_{\mathrm{i} 0}\right)+\mathrm{c}$

It is clear that either barotropic or surface currents with a relatively rapid decay scale will correlate with in situ currents at depth, $\mathbf{v}(\mathbf{z})$. Overall, current variations are likely to result in higher correlations with altimeter data than temperature variations and were found to account for $\sim 10 \%$ more of the altimeter (gradient) variance.

Finally, we note that the ratio of kinetic to potential energy is $\mathrm{k}^{2} \mathrm{Ro}^{2}$ for westward propagating structure with wave number $\mathrm{k}$, where Ro is the Rossby radius. For eddies or waves of similar scale with current structure defined by $\mathrm{v}_{\mathrm{i}}=\mathrm{v}_{\mathrm{i} 0} \mathrm{e}^{-z / b}$, the ratio of the baroclinic potential energy per unit volume due to isotherm displacement to the barotropic potential energy of the surface displacement divided by water depth, $\mathrm{H}$, (for unit volume comparison) will relate to $\sim \mathrm{B}^{2}$ or $=\mathrm{HN}^{2} \mathrm{~B}^{2} / g \sim \mathrm{HBe}^{-z / b} / b \sim 4000$ near the surface where $\mathrm{H} \sim 4000 \mathrm{~m}$.

Study domain and interpretation of longer eight year altimeter data time series

Size of the study region. The zonal region of applicability of the results can be assessed from the 'Hecla' section (Figure 8) 
which shows two wavelengths of the dynamic structure with similar vertical baroclinic structure extending over a $\sim 1000 \mathrm{~km}$ zonally. Maps of altimeter anomaly showing the applicability of the results have already been presented (Pingree et al., 1999). The meridional scale will be the eddy size or the latitude variability of westward propagating dynamic structure or at least $1 / 2$ a wavelength of the propagating structure $\sim 270 \mathrm{~km}$. Within this region the only adjusting value for the temperature equations will be the reference depth of the isotherm. The $10^{\circ} \mathrm{C}$ is fairly level zonally but warmer isotherms rise to the east and colder isotherms descend. Meridionally, the $10^{\circ} \mathrm{C}$ isotherm rises with a slope of $\sim 0.6 \times 10^{-3}$. However, it is expected that similar simple but different correlations will exist in other domains so that the internal structure of the ocean may be pieced together using a number of matching study domains where longterm in situ measurements have been carefully made. For longer wavelength structure or circulation, it is expected that there will be different responses for zonal and meridional changes with a wind stress that is largely east-west.

Although the dynamic SST is of relatively low amplitude, SST data are readily available (Figure 11) and the same structures seen in the 'Hecla' section can be identified in SST maps over $\sim 1000 \mathrm{~km}$ scale so in this sense the applicability of the study domain can be extended to westward propagating SST anomalies. Sea surface temperature values were extracted from the COADS data for the position of Rig 155 and the annual signal was removed from the SST data values to give a SST or $\mathrm{T}_{0}$ anomaly. Corresponding sla values were also extracted with the annual signal removed. The resulting $r^{2}$ correlation value between $\mathrm{T}_{0}$ and sla (minus annual signal) was $r^{2} \sim 0.1$ (with $\mathrm{N}=60$ ). This is the value to which the surface values given in Figure 7 should be extended. This relatively low surface value can be interpreted as showing that altimeter remote sensing is more sensitive to dynamic ocean structure than infra-red remote sensing in this region.

It is a simple matter to use the derived results to estimate the amplitude of surface currents, $\mathrm{v}_{\mathrm{o}}$, or geostrophic currents that could be derived from remote sensing, from the 'Hecla' temperature section (Figure 8) since this section provides the internal wave number for the near semi-annual structures. Take the internal displacement of isotherms, n, as

$\mathrm{n}=\mathrm{n}_{\mathrm{o}} \cos (\mathrm{kx}-\sigma \mathrm{t})$

where $\mathrm{k}$ is the wavenumber of structure, $\sigma$ is the near semiannual frequency and $\mathrm{t}$ is time.

The corresponding near semi-annual sea surface displacement, a, with amplitude, $\mathrm{a}_{\mathrm{o}}$, is estimated as $\mathrm{a} / \mathrm{n} \sim r^{2} / \mathrm{B}$, (or $\sim 1 / 860$ from Table 1). Substituting values in eqn 1 gives

$\mathrm{v}_{\mathrm{o}}=-\mathrm{gkn}_{\mathrm{o}} r^{2} /(\mathrm{fB}) \sim 20 \mathrm{~cm} \mathrm{~s}^{-1}$

where estimates of $\mathrm{k} \sim 2 \pi / 520 \mathrm{~km}, r^{2}=2 / 3, \mathrm{~B}=650, \mathrm{n}_{\mathrm{o}}=$ $125 \mathrm{~m}$ (250 m peak to trough displacement in the upper $\mathrm{km}$ ) have been derived here and $\mathrm{f}=7.84 \times 10^{-5} \mathrm{~s}^{-1}$ and $\mathrm{g}=9.8 \mathrm{~m} \mathrm{~s}^{-2}$ at $32.5^{\circ} \mathrm{N}$. The value of $\mathrm{v}_{\mathrm{o}} \sim 20 \mathrm{~cm} \mathrm{~s}^{-1}$ is in close agreement with the amplitude of the north component of semi-annual periodicity, $\mathrm{v}-\mathrm{SAP}=18 \mathrm{~cm} \mathrm{~s}^{-1}$, at $35.5^{\circ} \mathrm{W}$ (Rig 155 position) determined in Pingree \& Sinha (2001). Hence we can interpret cross sections of the isotherm displacements in terms of surface currents. Of course these values of $\mathrm{v}_{\mathrm{o}}$ will be lower than the maximum values found in westward eddies rather than westward waves (also defined by eqn 13) since the section does not go cleanly through the eddy centres (see Figure 11). If we assume a cosine distribution for westward moving eddy centres at $32.5^{\circ} \mathrm{N}$, then the amplitude of the eddy currents or swirl current becomes $\pi / 2 \mathrm{v}_{\mathrm{o}} \sim 30 \mathrm{~cm} \mathrm{~s}^{-1}$. The standard deviation of temperature in the upper layer is $\sim 1^{\circ} \mathrm{C}$ and this is also the value $\left(\sim 0.9^{\circ} \mathrm{C}\right)$ found for the standard deviation of SST anomaly at $32.5^{\circ} \mathrm{N}$ near the mooring position (see Figure 11). Hence although the spatial SST changes are small in comparison to the annual cycle of SST they are dynamically important and matched by surface currents of $\sim 20 \mathrm{~cm} \mathrm{~s}^{-1}$ amplitude, or said another way, $\left(1^{\circ} \mathrm{C}\right)^{2}$ of temperature SST variance is equivalent to $1 / 2\left(20 \mathrm{~cm} \mathrm{~s}^{-1}\right)^{2}$ of surface geostrophic current variance.

We also note that the kinetic energy (KE) per unit mass based on the speed (with $25 \mathrm{~h}$ averaging) of an Argos buoy (25687) drogued at $200 \mathrm{~m}$ depth in S0 for a 200 day period, travelling westward from $\sim 33.3^{\circ} \mathrm{W}$ to $\sim 38.6^{\circ} \mathrm{W}$ along $\sim 32.5^{\circ} \mathrm{N}$ was $343 \mathrm{~cm}^{2} \mathrm{~s}^{-1}$ (Pingree, 1997), so the propagating $\mathrm{KE}$ or variance was one or two orders of magnitude greater than the non-propagating annual signal for this region. In terms of temperature standard deviation, the results showed that the standard deviation of in situ temperature in the upper ocean below the seasonal thermocline was $\sim 0.8^{\circ} \mathrm{C}$ (see eqns 3 and 5), whereas the SST cycles between $\sim 19^{\circ} \mathrm{C}$ and $\sim 26.5^{\circ} \mathrm{C}$ (with annual maximum near first week in September), an annual range of $7.1^{\circ} \mathrm{C}$, equivalent to a total standard deviation of $\sim 2.7^{\circ} \mathrm{C}$. Hence, although the SST variance is an order of magnitude greater than the measured in situ temperature variance it is not the sensitive dynamic signal. The ratio of the annual component of SST variance to the SST variance with the annual signal removed, the SST or $\mathrm{T}_{0}$ anomaly, was 7.5; or equivalently the $\mathrm{SD}$ for the $\mathrm{T}_{0}$ anomaly was $\sim 0.9^{\circ} \mathrm{C}$, comparable with $\mathrm{T}_{1}$ and $\mathrm{T}_{2}$.

Extending the applicability of the results with time. Remote sensing altimeter and infra-red data from satellites will extend to the foreseeable scientific future. The eight year altimeter data time series at $32.5^{\circ} \mathrm{N}$ (Figure 12) plotted against longitude and Julian Day (Wilimovsky, 1990) does not readily reveal the dynamic structure of the ocean because the annual signal is of comparable size and nonpropagating in the study region. Intense westward propagating features can be seen, for example, the depression labelled 0 (i.e. Storm 0) and this is the most dominant structure so far observed in the North Atlantic near this latitude since the altimeter mission started (1992). A much improved dynamic structure at the rig latitude $\sim 33^{\circ} \mathrm{N}$ can be derived by removing the annual signal (Figure 13). At the position of the mooring, the annual signal for the longer time series sla data was $4.8 \mathrm{~cm}$ with a maximum amplitude in mid-September and this single component accounts for $30 \%$ of the total sla variance for the $8-y$ period. Other climate signals in the period band $>1$ year to 8 years are retained.

The eight year series (Figure 13) is readily interpreted. Eddies have wavelike properties and near the rig position the periodicity of structure is near semi-annual (Figure 5) and the westward travel speed is $2.7 \mathrm{~km} \mathrm{~d}^{-1}$ near $35^{\circ} \mathrm{W}$. 
The value of the westward travel speed confirmed the Lagrangian measurements and is larger than the fastest mode 1 Rossby Wave phase speed $\left(\sim 2.3 \mathrm{cms}^{-1}\right)$ for the region. This discrepancy between measurement and theory has been addressed by Killworth et al. (1997). We note that in the region to west $\left(\sim>40^{\circ} \mathrm{W}\right.$ at $\left.\sim 33^{\circ} \mathrm{N}\right)$ the westward travel speed increases to $\sim 5 \mathrm{~cm} \mathrm{~s}^{-1}$ so further theoretical refinements may be necessary. A further difference between theory and measurement might be that Rossby Waves with their associated north-south velocity components are not very coherent in a meridional sense with a coherent north component extending only to about the eddy scale, a few $(\sim 5$, see later) degrees of latitude at most. In addition, the wave number of the structure is not at the long wave limit for maximum westward propagation, with $\mathrm{k}^{-1} \sim 80 \mathrm{~m}$ and a Rossby radius $\sim 34 \mathrm{~km}$, which reduces the long wave westward speed by $\sim 15 \%$. The in situ data, being also eddy-like, show comparable east-west orbital velocities expected for swirl motion (Figures $9 \& 10$, with near east upper layer currents reaching $\sim \pm 50 \mathrm{~cm} \mathrm{~s}^{-1}$ ). In the 8 -y period, $\sim 15$ travel curves for positive or negative structure can be seen, $\sim 9$ after S0 and 6 before, giving a period of $\sim 200$ days and a wavelength of $540 \mathrm{~km}$ for the repeating structure. Fourier analysis of the longer altimeter data shows dominant $\sim 200$ day periodicity or rather, two periods (harmonics, 16, semi-annual, and 14), 183 day and 209 day, producing the amplified structure with more positive levels seen near $35^{\circ} \mathrm{W}$ in 1995 and 1999. It is evident that the amplified structure or group also moves westward with the travel contours, such that it is near $25^{\circ} \mathrm{W}$ in $1994 / 1995$ but nearer $40^{\circ} \mathrm{W}$ in $1995 / 1996$, so the wave aspects of the structures are non-dispersive. Finally, we note that the mesoscale cyclonic structure is deeper or more intense than the anticyclonic structure (see also Figure 5) and this is in agreement with the results from the 'Hecla' section (in space, Figure 8) and the thermistor chain data (in time, Figure 6).

Since there is a semi-annual peak in the spectrum, we analysed the whole Atlantic for the semi-annual signal and found a number of regions where the semi-annual signal exceeded the annual signal (see Methods). A coherent region was also found for the study area between $30^{\circ} \mathrm{W}$ and $40^{\circ} \mathrm{W}$ centred at $\sim 33^{\circ} \mathrm{N}$. The phase structure was coherent from $30^{\circ}-35^{\circ} \mathrm{N}$ and showed a wave propagating to the west from $24^{\circ} \mathrm{W}$ to $40^{\circ} \mathrm{W}$ with a wavelength of $\sim 500 \mathrm{~km}$ and the wave phase at the mooring position $\left(\sim 35.5^{\circ} \mathrm{W}\right)$ was $\sim 180^{\circ}$. This gives a trough at $0^{\circ}$ or at the start of the year at the rig position and this is consistent with the timing of the measured Storm temperature structure which shows cooling near the start of the year (and mid year, see Figure 5). A mean (from $30^{\circ}-35^{\circ} \mathrm{N}$ ) semi-annual amplitude of $\sim 2 \mathrm{~cm}$ gives a north component of current of $\sim 3 \mathrm{~cm} \mathrm{~s}^{-1}$ (see eqns 1 or 14 ). This is about $15-20 \%$ of the measured north current signal at $32.5^{\circ} \mathrm{N}$. Longer altimeter records would be required to see whether this is a genuine westward propagating semi-annual wave with a dominant north current component $(\sim \times 3$ east component, which was at quadrature, with anticyclonic flow around a high and cyclonic flow around a trough or negative sla) or what will inevitably be detected by Fourier analysis of a limited period (eight years) of data when part of the signal (19961998, Figure 5) has been shown to have a marked measured semi-annual periodicity. In any event, it would not be clear evidence for plane Rossby Wave propagation at this latitude since this semi-annual period with its associated wavenumber does not fit the plane Rossby Wave dispersion relation, giving a phase speed of $1.8 \mathrm{~cm} \mathrm{~s}^{-1}$ (Pingree \& Sinha, 2001) rather than the value of $3.1 \mathrm{~cm} \mathrm{~s}^{-1}$ derived from the semi-annual altimeter analysis.

Rapid Climate Change (1990-2002). The winter North Atlantic Oscillation (NAO) Index changed markedly between extreme positive and negative values from the winter of 1994/1995 to the winter of 1995/1996 (GarciaSoto et al., 2002). The extreme winter negative index of 1995/1996 was correlated with warm winter Eastern North Atlantic Central Water along the European Slope Margin from subtropical to subpolar regions, $\sim 35^{\circ} \mathrm{N}-$ $65^{\circ} \mathrm{N}$. The year 1998 was also a Navidad year, as was 2001, showing marked increases in winter (January) temperature from the Subtropical Front to the Faeroe-Shetland Channel, north of Scotland, along the north eastern margin of the Ocean. In Pingree (2002), it was shown that during periods of positive NOA Index, both the North Atlantic Current and the complete Subtropical Gyre intensify or increase in strength. The ocean lag with respect to the wind forcing (or NAO Index) is just under one year. Years of marked Gyre transport were 1995 and 1999/2000. The intensification of eddy/wave activity in 1995 and 1999 might result as the Subtropical Gyre adjusts to its increased strength in response to positive NAO Index forcing. It was further shown that the slope current or Navidad years were out of phase with years of increased Gyre transport and that 1996-1998 corresponded to a period of weak flow in the North Atlantic Current. The West European rapid ocean climate change results of Pingree (2002) can be summarized simply. The slope current switches off as the wind stress curl over the ocean increases. Or, when the wind stress is reduced, a poleward eastern boundary current starts to flow. The biological impact may be marked, for example, tropical and subtropical species may find themselves displaced poleward of their northern limits of distribution along the eastern margin of the Ocean in years of flow. Notable Navidad years for Eastern Boundary poleward flow were 1990, 1996, 1998, 2001 (Garcia-Soto et al., 2002).

\section{DISGUSSION AND SUMMARY}

Both in situ measurement of temperature and altimeter remote sensing data show a dominant near semi-annual structure in the Subtropical North Atlantic Ocean. A comparison of in situ measurements with altimeter remote sensing data over a $2-y$ period shows that the altimeter sla has a maximum correlation with isotherm displacements at $560 \mathrm{~m}$ depth, at the position $32.5^{\circ} \mathrm{N} 35.5^{\circ} \mathrm{W}$ of the current meter mooring. At this level, the sla data represent $\sim 2 / 3$ of the measured temperature or isotherm displacement variance. The level corresponds closely to the region of maximum vertical temperature gradient in the permanent thermocline where oscillations were found to be near semi-annual. Maximum peak to trough displacement amplitudes for isopycnals (isotherms) increased from near zero at the sea surface to 250-300 $\mathrm{m}$ at a depth of about $330 \mathrm{~m}$ and comparable displacements $(\sim 250 \mathrm{~m})$ 
are maintained (to $\sim \pm 20 \%$ ) to $1400 \mathrm{~m}$. Deep CTD profiles show similar displacements to near the sea-floor $\sim 3.8 \mathrm{~km}$ depth. The magnification of altimeter sea surface displacement with respect to the correlated displacement of the permanent thermocline was $\sim 650$. In the euphotic zone $\sim 0-100 \mathrm{~m}$ depth, isopycnal displacement is relatively small with displacements of the seasonal thermocline of order $10 \mathrm{~m}$ at $80 \mathrm{~m}$ depth in late summer (see Figure 2). The correlation between altimeter anomaly and SST anomaly was only $r^{2} \sim 0.1$.

The measured in situ current structure was also markedly semi-annual, though eddy motion can reduce this characteristic in the east component relative to the north component. For currents, correlations with sla gradient gave the highest $r^{2}$ value for near surface currents at the same position in the subtropical North Atlantic region. The linear regression coefficient for currents at $242 \mathrm{~m}$ depth is 0.92 with

$\mathrm{u}_{\mathrm{g}}\left(\mathrm{cm} \mathrm{s}^{-1}\right)=0.92 \mathrm{U}_{1}($ at $242 \mathrm{~m})+0.2$

Eqn 15 is the complement of eqn 8 which has a slope coefficient of 0.80 . The product of the linear coefficients is $r^{2}=0.80 \times 0.92$, or $r^{2}=0.74$ (Table 1). If the altimeter data were exact and without error, then the value of 0.8 could mean that the displacements at the sea surface were not balanced geostrophically or that the geostrophic current amplitudes at the sea surface were reduced with depth or with respect to conditions at $242 \mathrm{~m}$ (see eqns $8 \& 9$ ). If the current meter was only measuring geostrophic motion then the coefficient 0.9 in eqn 15 could mean that the surface geostrophic values were less or that the altimeter data with inherent noise or coarser sampling only measures $90 \%$ of the full signal.

By contrast with temperature, the correlation results for geostrophic current (or sla gradient) with in situ current were found to be essentially uniform in the upper $750 \mathrm{~m}$ although the currents at $742 \mathrm{~m}$ were much reduced $(\sim 0.4)$. The sla gradient accounts for $\sim 3 / 4$ of the observed current variance from the sea surface to a depth of $\sim 750 \mathrm{~m}$. The $r^{2}$ value falls to about $40 \%$ at $\sim 1400 \mathrm{~m}$. Although the temperature amplitude structure was not in good agreement with a mode 1 Rossby Wave, the ratio of the north current component at $242 \mathrm{~m}$ to that at $742 \mathrm{~m}$ was $\sim 2.0$, consistent with the Rossby Wave vertical structure function (see figure 23 of Pingree \& Sinha (2001)), but the correlation coefficient at $\sim 1400 \mathrm{~m}$ was not negative as might be expected. The decay of currents with depth is related to the value $(\sim 650)$ of the inverted displacement magnification of the permanent thermocline with respect to the sea surface displacement.

The area of applicability of the study domain was extended in space with in situ measurements from an Atlantic crossing near $33^{\circ} \mathrm{N}$ and in time by separating the thermodynamic or buoyancy flux signals from the dynamic structure of sla or SST. The amplitude of the non-propagating seasonal sla signal in the study region was $\sim 5-6 \mathrm{~cm}$ and in agreement with seasonal variations of dynamic height measurements. The annual amplitude for zonal and meridional currents in the study region was $\sim 1 \mathrm{~cm} \mathrm{~s}^{-1}$ but in the adjacent Subtropical/Azores Front region the amplitude for zonal currents increased to $4 \mathrm{~cm} \mathrm{~s}^{-1}$. In an earlier paper (Pingree \& Sinha, 1998), it was shown that a sea level difference of $\sim 1 \mathrm{~cm}$ corresponded to a transport of $\sim 1 \mathrm{~Sv}$. These additional in situ measurements show that a sea surface height amplitude of $\sim 1 \mathrm{~cm}$ zonally is related to a north component of surface geostrophic current with an amplitude of $\sim 1 \mathrm{~cm} \mathrm{~s}^{-1}$ and an inverted internal displacement of the permanent thermocline of $\sim 7 \mathrm{~m}$ for mesoscale structure in this region.

A summary of westward propagating sla anomalies at $32.5^{\circ} \mathrm{N}$ over an $8-y$ period in Julian Days was presented and interpreted based on the 2-y in situ inter-comparison measurement period. Each data point was Fourier analysed for the annual component which was then removed from the 8-y data period. The time and distance lines for data were superposed on the sla travel curves (Figure 13). Storm 0 (S0) has a continuous travel curve of $>500$ days. The longer altimeter time series shows that the dominant period associated with the wavelike properties of the eddies is $\sim 200$ days rather than semi-annual, though a dominant semi-annual north component was isolated. The eight year series also shows that the hydrographic measurements of S0 were conducted in a year (1995) of more intense wave or eddy activity. The longer term sla trends relate to the circulation of the North Atlantic Ocean such that increasing positive levels in a central region mean a more intense Subtropical Gyre circulation and a stronger North Atlantic Current, correlating but lagging (by a year) an extreme positive NAO Index. Poleward flow in years following a period of extreme negative NAO Index forcing will bring the northern distribution limit of subtropical species northward.

Travel curves for westward propagating ocean structures at a fixed latitude are well-known (Tokmakian \& Challenor, 1993) and have been variously described as revealing westward propagating Rossby Waves (Chelton \& Schlax, 1996; Cipollini et al., 1997; Born et al., 1998), eddies (Pingree \& Sinha, 1998) or eddies with wavelike properties (Pingree \& Sinha, 2001). Related structures are also evident in infra-red sea surface temperature data (Halliwell \& Cornillon, 1991; Halliwell et al., 1991) and ocean colour (Pingree et al., 1999, Cipollini et al., 2001; McGillicuddy et al., 2001) and it has been postulated that planetary Rossby Waves may be important in pumping nutrients to ocean surface waters (Uz et al., 2001; Siegel, 2001). A future goal would be to address the importance of westward propagating structure on chlorophyll- $a$ production or the transfer of inorganic nutrients to the euphotic zone and the changes in light levels at the depth of the seasonal thermocline due to the oscillation of isotherms in the subtropical domain studied. Here we have shown a seasonal or climate link where the SeaWiFS chlorophyll- $a$ annual and semi-annual signals follows the negative (or upwelling) sla cycles along the equator. In the Gulf of Guinea, maximum chlorophyll- $a$ responses in July/ August follow (by $\sim 10$ days) upwelling or tilting and lifting of the thermocline due to the Guinea Current flowing east in the Guinea Coastal upwelling region and the South Equatorial Current flowing west in the Congo Plume region.

Altimeter data were received from ESA Grant A02.UK121 and ENVISAT Grant A03 158. Processed altimeter data were also supplied by AVISO Altimetry/CLS Space Oceanography Division, Toulouse, France. 


\section{REFERENCES}

AVISO/Altimetry, 1996. AVISO CD ROM Users Manual for Merged TOPEX/POSEIDON products, AVI-NT-02-100, Edn 3.0.: CLS.

Born, G., Leben, R., Fox, C. \& Tierney, C., 1998. Wave monitoring and analysis in the Pacific. AVISO Altimetry Newsletter, no. 6, 16-17.

Boyd, J.D. \& Linzell, R.S., 1993. The temperature and depth accuracy of Sippican T-5 XBTs. Fournal of Atmospheric and Oceanic Technology, 10, 128-136.

Chelton, D.B. \& Schlax, M.G., 1996. Global observations of oceanic Rossby waves. Science, New York, 272, 234-238.

Cipollini, P., Cromwell, D., Challenor, P.G. \& Raffaglio, S., 2001. Rossby waves detected in global ocean colour data. Geophysical Research Letters, 28, 323-326.

Cipollini, P., Cromwell, D., Graham, D., Quartly, G.D. \& Challenor, P.G., 2000. Remote sensing of oceanic extratropical Rossby waves. In Satellites, oceanography and society (ed. D. Halpern). Elsevier Oceanographic Series, 63, 99-123.

Cipollini, P., Cromwell, D., Jones, M.S., Quartly, G.D. \& Challenor, P.G., 1997. Concurrent altimeter and infrared observations of Rossby wave propagation near $34^{\circ} \mathrm{N}$ in the northeast Atlantic. Geophysical Research Letters, 24, 889-892.

Cromwell, D., Challenor, P.G., New, A.L. \& Pingree, R.D., 1996. Persistent westward flow in the Azores Current as seen from altimetry and hydrography. Fournal of Geophysical Research, 101, 11923-11933.

Fasham, M.J.R., Platt, T., Irwin, B. \& Jones, K., 1985. Factors affecting the spatial pattern of the deep chlorophyll maximum in the region of the Azores Front. Progress in Oceanography, 14, 129-165.

Halliwell, G.R. \& Cornillon, P., 1991. Westward-propagating SST anomaly features in the Sargasso Sea. Fournal of Physical Oceanography, 21, 635-649.

Halliwell, G.R., Ro, Y.J. \& Cornillon, P., 1991. Westwardpropagating SST anomalies and baroclinic eddies in the Sargasso Sea. Fournal of Physical Oceanography, 21, 1664-1680.

Hydrographic Department, 1982. Africa Pilot, Vol. 1. Taunton: Ministry of Defence.

Garcia-Soto, C., Pingree, R.D. \& Valdes, L., 2002. Navidad development in the southern Bay of Biscay: climate change and swoddy structure from Remote Sensing and in situ measurements. Fournal of Geophysical Research, in press.

Kelly, K.A. \& Watts, D.R., 1994. Monitoring Gulf Stream transport by radar altimetry and inverted echo sounders. Fournal of Physical Oceanography, 24, 1080-1084.

Killworth, P.D., Chelton, D.B. \& deSzoeke, R.A., 1997. The speed of observed and theoretical long extra-tropical planetary waves. Fournal of Physical Oceanography, 27, 1946-1966.

Le Traon, P.Y., Nadal, F. \& Ducet, N., 1998. An improved mapping method of multi-satellite altimeter data. Fournal of Atmospheric and Oceanic Technology, 15, 522-534.

McGillicuddy Jr, D.J., Kosnyrev, V.K., Ryan, J.P. \& Yoder, J.A., 2001. Covariation of mesoscale ocean color and sea-surface temperature patterns in the Sargasso Sea. Deep-Sea Research II, 48, 1823-1836.

Mouriño, B., Fernández, F., Escánez, J., Armas, D., Giraud, S., Sinha, B. \& Pingree, R.D., 2002. A SubTropical Oceanic Ring of Magnitude (STORM) in the Eastern North Atlantic: physical chemical and biological properties. Deep-Sea Research II, in press.

Mouriño, B., Fernández, F., Serret, P., Harbour, D.S., Sinha, B. \& Pingree, R.D., 2001. Variability and seasonality of physical and biological fields at the Great Meteor Tablemount (subtropical NE Atlantic). Oceanologica Acta, 24, 167-185.

New, A.L., Jia, Y., Coulibaly, M. \& Dengg, J., 2001. On the role of the Azores Current in the ventilation of the North Atlantic Ocean. Progress in Oceanography, 48, 163-194.
Pingree, R.D., 1997. The eastern Subtropical Gyre (North Atlantic): flow rings recirculations structure and subduction. Fournal of the Marine Biological Association of the United Kingdom, 77, 573-624.

Pingree, R.D., 2002. Ocean structure and climate (Eastern North Atlantic): in situ measurement and remote sensing (altimeter). Fournal of the Marine Biological Association of the United Kingdom, 82, 681-707.

Pingree, R.D., Garcia-Soto, C. \& Sinha, B., 1999. Position and structure of the Subtropical/Azores Front region from combined Lagrangian and remote sensing (IR/altimeter/SeaWiFS) measurements. Fournal of the Marine Biological Association of the United Kingdom, 79, 769-792.

Pingree, R.D. \& New, A.L., 1995. Structure, seasonal development and sunglint spatial coherence of the internal tide on the Celtic and Armorican shelves and in the Bay of Biscay. Deep-Sea Research, 42, 245-284.

Pingree, R.D. \& Sinha, B., 1998. Dynamic topography (ERS-1/2 and Seatruth) of Subtropical Ring (STORM 0) in the Storm corridor $\left(32-34^{\circ} \mathrm{N}\right.$, Eastern Basin, North Atlantic Ocean). Fournal of the Marine Biological Association of the United Kingdom, 78, 351-376.

Pingree, R.D. \& Sinha, B., 2001. Westward moving Waves or Eddies (Storms) on the Subtropical/Azores Front near $32.5^{\circ} \mathrm{N}$ ? Interpretation of the Eulerian currents and temperature records at moorings $155\left(35.5^{\circ} \mathrm{W}\right)$ and $156\left(34.4^{\circ} \mathrm{W}\right)$. Journal of Marine Systems, 29, 239-276.

Pingree, R.D., Sinha, B., New, A.L., Waddington, I., Head, R.N. \& Nechvolodov, L.V., 1996. Will deep subtropical Ring 'Storm Physalia' cross the Mid Atlantic Ridge and reach America? Fournal of the Marine Biological Association of the United Kingdom, 76, 553-567.

PML, 1995. RRS Charles Darwin Cruise 97/95 Report, 12 October 19956 November 1995. Plymouth: Plymouth Marine Laboratory.

Richardson, P.L., Bower, A.S. \& Zenk, W., 2000. A census of Meddies tracked by floats. Progress in Oceanography, 45, 209-250.

Richardson, P.L., Hufford, G.E., Limeburner, R. \& Brown, W.S., 1994. North Brazil Current retroflection eddies. Fournal of Geophysical Research, 99, 5081-5093.

Siegel, D.A., 2001. The Rossby rototiller. Nature, London, 409, 576-577.

Spindel, R.C. \& Desaubies, Y.J.-F., 1983. Eddies and acoustics. In Eddies in marine science (ed. Allan Robinson), pp. 525-541. Berlin: Springer-Verlag.

Slutz, R.J., Lubker, S.J., Hiscox, J.D., Woodruff, S.D., Jenne, R.L, Joseph, D.H., Steurer, P.M. \& Elms, J.D., 1985. Comprehensive Ocean-Atmosphere Data Set; Release 1. NOAA Environmental Research Laboratories, Climate Research Program, Boulder, CO, 268 pp.

Stammer, D., Hinrichsen, H.-H. \& Kase, R.H., 1991. Can Meddies be detected by satellite altimetry? fournal of Geophysical Research, 96, 7005-7014.

Tokmakian, R.T. \& Challenor, P.G., 1993. Observations in the Canary Basin and the Azores Frontal Region using Geosat data. Fournal of Geophysical Research, 98, 4761-4773.

Uz, B.M, Yoder, J.A. \& Osychny, V., 2001. Pumping of nutrients to ocean surface waters by the action of propagating planetary waves. Nature, London, 409, 597-600.

Wilimovsky, N., 1990. Misuses of the term "Julian Day". Transactions of the American Fisheries Society, 116.

Woodruff, S.D., 2001. COADS updates including newly digitized data and the blend with the UK Meteorological Office Marine Data Bank and Quality control in recent COADS updates. Proceedings of Workshop on Preparation, Processing and Use of Historical Marine Meteorological Data, Tokyo, Japan, 28-29 November 2000, pp. 9-13 and 49-53. Japan Meteorological Agency and the Ship \& Ocean Foundation.

Submitted 14 March 2002. Accepted 7 August 2002. 